Journal Article

\title{
Participatory action research (PAR) research: critical methodological considerations
}

Livingston, W., Perkins, A.

This article is published by Emerald. The definitive version of this article is available at:

https://www.emeraldinsight.com/doi/abs/10.1108/DAT-08-2017-0035

\section{Recommended citation:}

Livingston, W., Perkins, A. (2018), 'Participatory action research (PAR) research: critical methodological considerations', Drugs and Alcohol Today, https://doi.org/10.1108/DAT-08-2017-0035 


\section{EEmerald $\begin{aligned} & \text { Drugs and Alcohol } \\ & \text { Today }\end{aligned}$}

\section{Participatory Action Research (PAR) Research - Critical methodological considerations}

\begin{tabular}{|r|l|}
\hline Journal: & Drugs and Alcohol Today \\
\hline Manuscript ID & DAT-08-2017-0035.R1 \\
\hline Manuscript Type: & Research Paper \\
\hline Keywords: & $\begin{array}{l}\text { Alcohol and Drugs, Involvement, Participatory Action Research, Research } \\
\text { Methodologies, Substance Use, Research Ethics }\end{array}$ \\
\hline \multicolumn{2}{|l}{} \\
\hline
\end{tabular}

SCHOLARONE ${ }^{m}$

Manuscripts 


\title{
Participatory Action Research (PAR) Research - Critical methodological considerations
}

\begin{abstract}
Purpose: The purpose of this paper is to explore a range of key deliberations with regards to adopting Participatory Action Research (PAR) and Privileged Access Interviewer (PAI) approaches and methodologies within research on substance use

Design/methodology/approach: This paper is a reflective piece, it adopts a mixture of applied practice and theory considerations. These conceptualisations capture what are still relatively early understandings and uses of such methodologies, acquired across several decades of research and service provision experiences. The paper is structured around some of the sequences of the research process and as such provides a broad framework for such approaches.
\end{abstract}

Findings: PAR and PAI approaches utilise several key theoretical considerations. There are many critical issues associated with adopting these approaches, including those of ethics, funding, involvement, language, resources and support. Three key principle reasons (moral, political and research based), help explain why we should see more adoption of such approaches in substance use related research.

Research limitations/implications: This paper represents author views which are by their nature very subjective.

Practical implications: Implementation of the key considerations highlighted within this paper can lead to an active adoption of PAR and PAI methodologies within alcohol and drug research. Increasing the use of such methodologies will allow commissioners, researchers and service providers to develop a more nuanced understanding of the experiences of and responses to alcohol and drug use.

Originality/value: This paper captures critical conversations at a time of increased calls for service user involvement across all aspects of alcohol and other drug provision, including evaluation and research.

Key Words: Alcohol and Drugs, Involvement, Participatory Action Research, Research Methodologies, Substance Use

\section{Introduction}


This paper is based explicitly on the current views of its named authors. However, like all research papers, it builds upon previous experiences and projects (for example Biskin et al 2013, Author et al 2011), and previous writing (Author 2016, 2017). Therefore, much of what is offered is the co-production of a range of other actors who have clearly shaped its formulation. Given its nature, it would be inappropriate to not start by stating, that this paper is the consequence of all the generous sharing by and with all those we have worked with across numerous years in research and service provision. We are grateful to them for educating us, and as such we feel advocates rather than originators of the sentiments contained within this paper.

Participant Action Research (PAR) combines two separate research concepts:

- Participation - active involvement of 'subjects' in the research process; and

- Action - defining social problems and solving them.

It sits within a spectrum of what is considered patient, public or service user involvement. The movement to increased participation is often concentrated on provision and receipt of health and social care services, but also includes research into the effectiveness of services too (Brett et al 2014, Voorberg 2015). An early defining model of this spectrum was Arnstein's (1969) ladder of citizen participation, which suggested a full spectrum from manipulation to citizen control. In research terms, we might suggest some of the positions along the spectrum as:

- Non-Participation (manipulation) - service users partake purely as respondents from whom data is collected.

- Degrees of moderate involvement - consultation or involvement in steering groups only.

- Significant involvement - delegated and designated roles within the research as researchers.

- Participatory Research - involved in the need for and commissioning of research, and/or as full team members from research bid through to final report.

The two concepts of PAR bring different elements and understanding to the research process. Firstly: 
Participatory - this is what Gilbert (2008) refers to as doing with and for, rather than on others. It is thus concerned with definitions of expertise and knowledge and who controls these. It comes with what Humphries (2008) identifies as having several principles:

- a bottom up approach with a focus on locally defined priorities, processes and perspectives;

- striving for equalising power among researchers and researched;

- a process characterised by a genuine dialogue between researcher and researched;

- control over definition of problems, methods, analysis and actions is with those most affected by the study;

- the emphasis is on processes as much as on outcomes; and

- the role of the researcher is one of facilitator and catalyst rather than director.

Secondly:

Action - proposes that action researcher and members of a social setting collaborate in the understanding of a problem and in the development of a solution based on this understanding (Bryman 2008). This is supported by an emphasis on:

- nonintrusive collaboration (including ownership of the project by the group);

- mutual trust and genuine respect;

- solidarity (all humanity is connected by a common journey and shared destiny);

- mutuality and equality (everyone's interests are important);

- a focus on process (informal interaction that goes beyond a detached working relationship and respects others' cultures); and

- language as an expression of culture and power.

Action research seeks intended consequences and expects elements of change to be experienced by all. It pursues to overtly improve the social situation, with both explicit practical application and political activity. It can occur across several activities, for example: organisational change, community development, new projects, practitioner research and social injustice.

The overall approach can be summarised as concerning itself with 'People, Power and Praxis' (Gilbert 2008) where traditional academic researchers translate their role into one of facilitating the goals of their co-researchers. Carey (2010) echoes these sentiments, in which three key considerations are raised: practical impediments, ethical implications and political 
dilemmas. He goes onto caution that there are possibilities that participation in research can mirror some of the current preoccupations in wider policy and provision, where participation may be encouraged or increased but not necessarily be successful in addressing the power dynamics; and may even exasperate them.

Privileged Access Interviewers (PAI) is a term that best captures why such methods are especially well suited for research inquiries into areas of activity and with people in experiences that are subject to societal marginalisation and often referred to as ' $h a r d$ to reach'. These include those of substance use. The approach is political apposite where there is a need to reach into certain populations, who are perhaps not readily captured by traditional research methodology. There are distinct overlaps with the ethnographic approaches drawn from social anthropology (Fine and Hancock 2017), and the essential role of those with access, as established through Whyte's (1993) seminal text and his relationship with Doc. Ennis and Wykes (2013) concluded that such involvement of service users in the research process enabled greater levels of recruitment to projects. Further, participatory approaches (i.e. those emphasising what can be considered as co-production), have a resonance and value in understanding the experiences of marginalised populations (Tedmanson 2016).

The principles of these approaches can, as most research techniques can, be applied to a range of design, data collection and analysis methods. This said, there is to some degree an inherent bias towards the subjective rather than the objective. Thus, many articulate for the use of an extensive range of qualitative written, visual and textual data collection methods (Bryant 2016), to compliment the traditional dominant paradigm for random control trials, statistics and surveys.

Within these discourses, the use of terminology implies ontological and methodological positions. The ethical, morale and methodological implications of this language are explored further on, but for consistency this paper, from hereon in, refers to those whom are actively involved in the research as participants and those who contribute or offer data examples as respondents. For expediency, it adopts substance use to capture the diversity of both 'substances' (alcohol, illicit, legal and illegal drugs) and 'use' (dependency, excessive, harmful, hazardous and recreational).

\section{Starting Points}

These approaches have several assumptions (or givens) that might be considered as preexisting contextual considerations. 
Whilst the idea that a group of service users will just wander up to a university and ask for assistance in a research project might sound like the optimum and theoretical starting point (and indeed does occasionally happen), it is likely (and should be likely if co-production is indeed an increasingly wider commissioning, policy and service provision norm) that ideas are generated from within existing involvement activity. This could or should happen in substance use organisations or fora where meaningful participation is already well established with regards to other business or activities. This methodology therefore demands that initial conversations have been reciprocal and not unduly led by agencies/researchers to meet their own agendas. Thus, involvement prior to design or research bid application, moves research further along the possible spectrum of participation.

From here it is appropriate to have one or two dedicated conversations/meetings that scope out a project. These might well want to involve others not deemed as participants, as well as early project initiators. This is important to ensure that the research is supported, welcomed and has a good level of stakeholder engagement and involvement from the start. These early conversations need to include explicit exploration of ethical and resourcing issues. Such solid foundations of shared understanding are important, to help ease future resistance, when goals are directed towards political change.

It is likely, if not desirable or expected, that such a stage maybe the precursor to a formal funding application. Although as outlined below, acquiring funding is not without its difficulties. Ideally in such instances, applications are made with participants rather than on their behalf.

It feels important to emphasise that, in these early meetings, service user and participant voice is strong and not of a singular or representative type. Indeed, some might argue they need to be the majority for it to be truly participative, and the involvement of other professionals and researchers is for consultation.

\section{Identifying and recruiting participants}

In many instances those individuals involved in the initial and scoping conversations may well be those identified as the participants or PAIs. It feels important that potential participation is invited across many roles and responding to a variety of interest and skills, such as: project advisories or consultants, full blown participants, advertisers, recruiters, respondents and supporters. While initial conversations may generate enough involvement, in many instances there is likely to be the need for further recruitment - especially for PAI type 
projects. This will need to follow a purposeful sampling methodology, using a combination of targeted advertisement (with active consideration given to mobile and social media methods) and snowballing through existing networks and relationships.

There comes a point in participatory methods, if this has not happened fully at inception, where any project needs to ensure its direction is highly participant led. At this juncture, the research team (PAI and supporting academics) need to possibly withdraw from wider stakeholder discussions and begin to enable an approach which is very much service led, rather than informed. The role of the (academic) researcher here, is to facilitate discussions and understanding among the participants, and support them to agree upon the specific methods of inquiry.

Substance use research has the possibility to see co-production beyond the service user group and partnership could see carers, families, practitioners or students become the participant population.

\section{Language and Terminology}

Early formulations of this paper, were borne out of and reflect struggles with language. Much research literature frequently refers to participants. When in the context of an understanding of genuine partnership involvement, what is being referred to is, those from whom data has been collected. The use of participant almost seems a hangover of a subject involved in a controlled experiment, rather than any sense of any co-production; the exceptions perhaps being those engaged in ethnography or discourse analysis. For us, the ambiguity and confusion was cleared by choosing to be firm in distinguishing between those from whom we collect data (respondents), and those who actively participate in the other aspects of the research process (participants).

While such deliberations, may appear of semantics, they are in fact rooted in issues of power. At the heart of them lies a transparent declaration of whether researchers are distinct from (expert and controlling), or sharing in the same human experience (indeed, most alcohol researchers are drinkers). The latter position begins to ask fundamental questions of whether one truth or measurable actuality exists, rather than being a construct of any given (research) process. Furthermore, it raises questions of who is the expert and in what capacity. It also suggests the equal validity of all research methods, rather than supporting a hierarchy of the traditional or dominant. Finally, it implies the assumption of a sharing of access to resources and rewards from the research process. 


\section{Ethics}

As research, normal ethical considerations and processes must be accounted for. Projects will need to undertake appropriate due research ethics processes. It is possible that where ethics boards are predominantly used to, or dominated by traditional positivist and experimental type research approaches, that understanding of, and support for, PAR approaches maybe more limited. However, it is our experience that ethical approval is gained when attention is paid to specific key considerations; notably issues of boundaries and researcher confidence.

These approaches have a resonance with ethnography, which in turn helps to inform the management (or not) of boundary issues. Researchers are considered, if not expected, to be an active part of the community. Indeed, it is the opposite of aloof non-participatory observation which, in terms of the politics of involvement, might be considered a more exploitative and unethical approach. Working within discreet populations, as accessed via a PAI, challenges the boundaries of what is considered normal confidentiality for other research methodologies. Tolich (2004) acknowledges that an overt understanding of this helps accept the limits in the principles of confidentiality. Insiders are more likely to recognise what other insiders have said. He concludes that internal confidentiality is distinct from external confidentiality, and suggests the assurances for protection against identification is with those who were not subjects of the research, rather than within the discreet population cohort or community.

Because the methodology described here is a) not as deterministic or predictable in its course of action and b) process orientated, then the ethical requirement is for confidence in the researcher and/or research team (as much as the prescription of methods) and the successful management of what can appear as more fluid boundaries between the researcher and the researched. Ethics committee confidence, is often, as with other methods and about relevant prior experience of the researcher. One of the authors (as a registered social worker) has found it is important to stress equally the oversight of practice and research ethics. Thus, the process of being held accountable to a professional regulatory body, compliment those of research ethics, as might a social work qualification compliment a $\mathrm{PhD}$. This is because many of the research ethics issues are foremost practice dilemmas.

As might be expected, there is also regular concern raised about the use of payments for participants in this area of research, and possibilities of monies being spent on alcohol or drugs. The ethical concerns often fall into two considerations: those of undue incentive to 
participate, and/or payment leading to risk of harm. However, many researchers have now clearly articulated why genuine participation (issues of power) require this group of users to be treated the same as others and that payment is a requisite (Fry et al 2006, Neale et al 2017, Sandberg 2008). The counter argument, therefore stems around payments as justifiable and fair reimbursement for time given and expenses occurred. The usual compromise is to provide individuals with high street shopping vouchers that cannot be exchanged for alcohol or cigarettes. Fry et al (2006) in their article conclude “...research payments are ethically acceptable in most circumstances of addictions research, but should be closely scrutinized in situations where these may exacerbate existing harms or create additional risks for participants and investigators" (p21). In extreme cases (i.e. street drug dealing or use of drugs by sex workers), then payment maybe the only way individuals can viably participate without loss of income earning time, and cash rather than any voucher system will be required (Sandberg 2008).

\section{Funding and research bids}

If a bid for a participatory project is to be made with clear evidence of involvement having informed it, then this involvement also needs funding. For traditional research, bid preparation activity, is part of the paid job role for academics. To ensure a parity and active involvement of others, it seems to be an important and logical consideration that some of the commissioning, policy and organisational fora (referred to above), is also able to create funds and resource capacity for appropriate involvement to inform potential research project starting points.

Even assuming this informed prior application involvement, one of the biggest barriers to getting such research projects off the ground, is often the successful acquisition of external funding. Research funds often sit in a competitive bid process, including blind peer review processes. These processes aspire to establish exactly what a research project is going to do, so how well detailed and predictable and/or reliable the methodology described is. These scoring methods often have a bias towards predictive/positivist experimental research over methods where determining the methodology is a part of the process and not fully determined prior to. Truly iterative and participatory approaches cannot provide such clarity before they have begun. In addition, and much like the ethics committee, the bids are assessed by panels of experts whose own experiences and understanding lie with controlled experiments, quantitative surveys and statistical modelling rather than qualitative involvement. Thus, there 
is a more inherent bias where participatory action approaches are neither understood, nor valued by those responsible for making such judgements. Typical of those sentiments is the following example that this author received from a recent 'friendly' reviewer post an award being made:

The use of participant researchers looks innovatory but pretty risky, and the sample size is very small. A small and potentially contentious methodology ... is unlikely to make a big difference to conclusions even if it worked.

This situation was recently acknowledged at the 2017 Alcohol Research UK Annual Conference, that in part has led to this special edition ${ }^{1}$.

\section{Data collection and analysis}

Whilst all forms of data collection tools can be used within participatory approaches, there is often an inherent leaning towards the intrapersonal and relationship based inquires, so frequently qualitative methodology. Whilst this may regularly be done through focus groups and interviews with schedules and a range of semi-structured questions, participatory approaches also lend themselves to the use of arts and other creative data capture approaches (Bryant 2016). Iterative approaches (typical of highly qualitative methods to data collection and analysis, whereby the experience of one element feeds into and refines the next) feel highly resonant with involvement approaches that are seeking to develop collective understanding and inform change.

It is possible that PAIs will at these junctures require some formative input from the academics or others within the research team. Thus, some of the research team need at times to translate facilitator into educator roles. So, the stage here is the sharing of expertise and knowledge about research techniques. Active consideration must be given to how material often used in other classroom settings, might need to be adapted for different audiences and learning needs.

It can be useful for PAIs to conduct the data collection method on each other. This provides: a) safe space to practice and receive feedback on, and refine techniques; and b) potential initial data that can be used within the wider data collection set. It might be that where data has been collected via film or audio, that the experienced researcher facilitator also watches and listens to the data, to provide supportive feedback to PAIs. Similarly, methods of analysis

\footnotetext{
${ }^{1}$ http://alcoholresearchuk.org/news/alcohol-research-uk-annual-conference-2017/
} 
might need to be explained or adapted to suit the needs of the PAI population. Consideration needs to be given to how best to support PAI involvement in analysis, so without assumption about access to and competence in IT. Some PAIs will want to be actively involved in the use of say SPSS or NVivo, but for others, a paper based or aural process maybe more suitable. Added reliability can occur with dual analysis approaches and then comparison of interpretations, so one approach for some PAIs and then a complimentary or additional one from the experienced or academic team members. An active but supportive role of experienced researchers within the cohort, can act as an additional process of quality assurance.

Recruitment of respondents, is likely to follow the same purposeful sampling methodology, using a combination of targeted advertisement (with active consideration given to mobile and social media methods) and snowballing through the existing networks and relationships used in PAI recruitment. Research that utilises peer and recovery groups means that individuals are known to each other within the community. Reflexive considerations of insider research approaches are required. Within this, identification of what proximity to potential respondents the PAIs are should be undertaken and used as inclusion or exclusion criteria; or passed onto another PAI within the project.

As PAIs spread out into the respective community and collect data, the experienced members of the team must be available for ongoing mentoring and support.

\section{Post data considerations}

Like other research methods, it is good to find a process by which emerging outcomes can be 'tested' out with those most likely to be impacted; and their responses to this, can shape any final conclusions. This could include taking initial findings back to any initiating fora or project advisory group. Active recovery communities, are also likely to provide on-going spaces where PAIs can test and make sense of emerging findings and conclusions.

It is likely that commissioners of research will want to see traditional 'research reports'. Further, any academics involved will want to, and be under pressure to, publish within peer review journals. In both these regards it is important that a) the opportunity to participate in 'writing up' is extended to PAIs, and b) irrespective of their involvement in the writing up, they are fully acknowledged (with consent) as co-authors. However, some projects, some groups etc., may also identify other non-written ways of wanting to present research findings. The adoption of these seems important, especially when considering research as both 
involved and action orientated. The change implied in action is likely to come from the widest of dissemination approaches.

Part of an action orientated methodology, which has process as important as outcomes, and considers outcomes for all, is about establishing sustainable PAI populations to then a) advise and support commissioning of future research, b) get involved in other projects, and c) act as peer mentors for future PAIs.

\section{Applied Framework}

It is possible to synthesise these considerations into a broad or proximate framework (model) comprising multiple stages.

Table 1: Model of stages of Participant Action Research approach

Insert table 1 here

Stages are iterative and overlap.

* These stages involve processes and organisations that are possibly external to the research team, so not fully within projects influence.

\section{Applied considerations}

This paper has been influenced by a diversity of previous and on-going research projects. However, given the considerations described, it has equally (if not more so) been informed by: many unsuccessful research bids, policy conversations, recovery group deliberations and reflections on the limitations of other research (including ours). This final section offers some of the learning we have acquired through these experiences.

PAR projects require a lot of (and at times freely given) energy and time, to ensure they are successful and sustainable. Several of the recent projects we have contributed to, have come out of long-term prior existing relationships. In other words, we have been actively involved in those fora discussed in the earlier part of this paper. This requires the academic researcher to spend time out and about in the community. Notably, we have been active members of recovery group networks and partnerships, often giving skills and time just like any other volunteer. Successful bids and projects are far more likely to come from already established and trusting relationships. We have, as is consistent with other research approaches, spent time doing early, small and unfunded pilot formulations. There is a need to continue, especially in economic climates where organisations and universities increasingly seek to 
restrict activities to those associated with computerised workload management agendas, for researchers to articulate that such time spent is necessary and valuable - especially as this is required to be off site. There is scope here to use organisational good citizenship or social good agendas to help meet these goals.

That participatory research, especially that involving action (for change), is as much a political, as it is research activity has therefore been one of the earliest and consistent messages. Biskin et al (2013) identify how even the simple task of social work students being encouraged in the classroom to expect service user and carer involvement, then meet resistance when wanting to account for whether they actually experience such in practice through a research project. So, whilst the service user involvement agenda is well established in substance use policy and provision agendas, it has yet to fully impact on the research world. Service user involvement has tended to primarily focus on the active participation of 'users' within treatment policy and provision agendas, rather than all users and ex users and including evaluation and research activities. In a recently completed review of the Welsh Governments 10-year alcohol (and drug) strategy, there was no PAR material amongst the relevant data sets and evaluations (Author et al 2017).

PAR and PAI approaches require inclusivity, and measured risk taking, if they are to succeed in being different and provide alternative explanations. We have had expressed to us concerns about PAIs interviewing those who are still actively using and exposing their own vulnerability to relapse (which assumes that PAIs are abstinent - which need not necessarily be the case) and how rigid (or not) any criteria for PAIs needs to be. This in turn, raises concerns for us, about whether researchers could be tempted into using PAI recruitment methodologies which are too strict, or too controlling, unless they themselves are prepared to take a few risks. PAR research ought to have the capacity to involve the whole spectrum of use or not. It is by its nature risk taking rather than risk adverse. When working with those in recovery as PAIs, it seems important to entrust to their already successfully developed notions of management and networks of support, rather than impose secondary researcher led frameworks. In fact, this makes us think that the success of PAI methodologies is also shaped by the characteristics of the research facilitator as it those of the PAIs recruited. Inclusivity and risk taking is thus required by those; commissioning, evaluating, overseeing and undertaking research. This seems to be only a fair and reciprocal to the risk we ask of others in entrusting and sharing their experiences with us. 
It feels as if over the last decade that the tide is finally turning. Indeed, the ARUK conference that is the precursor and inspiration for this special edition, is one obvious marker in this evolutionary journey. The explicit requirement to demonstrate involvement now appears to be a regular element of research bid application process requirements. Indeed, we have had more bid success of late (albeit maybe it is just that we have got a bit better at that bit). Notably, and very recently, an acceptance of the validity of the contribution these methods can make to enhance a complexity of methods in understanding national policy, has been acknowledged by Health Scotland in its commissioning of participatory methods as one of the streams within the evaluation of the impact of minimum unit pricing on harmful drinkers (NHS Health Scotland 2017).

\section{Concluding discussion}

At one level, there is nothing revolutionary in the principles of PAR or the methodological considerations explored within this paper. In part, they just feel like good conscious and reflexive research practices. However, at another level they seek to comprehensively resonate with aspirations for greater service user involvement in policy, practice and research activities. They have a feel of the ideological, a set of best laid aspirations and intentions. In this sense, the revolutionary comes from trying to meet as many of the ambitions as possible within each project, while contributing to an overall picture of change and challenge to an existing order that places expert led controlling experimental research at the pinnacle of perceived research hierarchies.

It is possible to reduce these complex discussions into three clear reasons why we should do and see more PAR/PAI research within alcohol and other drug studies. Firstly, this feels like a moral imperative. It is just the right thing to do. There has been an explosion in service user involvement in policy and service provision for substance use, and this needs to be matched by those researching such. Substances are widely consumed in society, including by researchers, the boundaries between an 'us and them' population often maintained by researchers, in this instance seems particularly false. It maybe that we need to turn the traditional research ethics preoccupation with protecting the vulnerable on its head, and into one of entrust, empower and respect. Secondly, this is a political issue. It raises fundamental questions of ontology and epistemology. A challenge to a dominant and vested interest about who does research and how. It asks questions of who is the 'expert'. It asks that research has an impact beyond the vested interest of the academic career and the research frameworks that 
academic institutions are increasingly judged by. Finally, and this is the purpose of research, new methodologies help create new understanding. There is more than one way to know how. It is a direct and appropriate response to Orford's (2008) seminal paper that argued for substance use research to move beyond its preoccupation with the randomised control trial. These are methodologies that enable us to gain a greater insight into the nature of experiences and relationships that are at the core of understanding why individuals develop difficulties regarding their substance use and how they might best be supported in developing healthier lifestyles.

It is possible to see two overlapping 'new' waves at work here. Where research has accepted the role of the sociological and qualitative to compliment the experimental and quantitative, it has yet to fully embrace moves to take this outside of the academy. Similarly, where substance use has embraced harm reduction and whole population agendas as a response to narrow disease model understandings, it has yet to fully reconcile itself with some of the newer debates and understanding about recovery and the increased control and involvement of those most affected. This paper simply seeks to contribute to these journeys.

\section{References}

Author A. (2016)

Author A (2017)

Author A et al (2011)

Author A, Author B, et al (2017).

Arnstein, S. R. (1969) "A Ladder of Citizen Participation," JAIP, 35(4). 216-224

Biskin, S. Barcroft, V. Livingston, W. and Snape, S (2013). Exploring service user and care involvement on a social work degree programme, Social Work Education: The International Journal, 32(3), pp.301-316.

Bradbury, H., and Reason, P. (2003). Action research: An opportunity for revitalizing research purpose and practices. Qualitative Social Work, 2(2), 155-175

Brett, J., Staniszewska, S., Mockford, C., Herron-Marx, S., Hughes, J., Tysall, C. and Suleman, R. (2014), Mapping the impact of patient and public involvement on health and social care research: a systematic review. Health Expectations, 17(5): 637-650 
Bryant, L. (2016) Introduction in Bryant, L. ed (2016) Critical and Creative Research Methodologies in Social Work, Routledge London (75-92).

Bryman, A. (2008) Social Research Methods Oxford, Oxford University Press.

Carey, M. (2010) Should I stay or should I go? Practical, ethical and political challenges to 'Service User' Participation within Social work research. Qualitative Social Work 10(2): 224-243.

Ennis and Wykes (2013) Impact of patient involvement in mental health research: longitudinal study The British Journal of Psychiatry 203: 381-386.

Fine, G. A and Hancock, B. H.(2017) The new ethnographer at work Qualitative Research 17(2): $260-268$.

Fry, C.: Hall, W; Ritter, A and Jenkinson, R (2006) The ethics of paying drug users the ethics of paying drug users who participate in research: a review and practical recommendations who participate in research: a review and practical recommendations. Journal of Empirical Research on Human Research Ethics,. 21-36.

Gilbert, N (2008) Researching Social Life London, Sage.

Humphries, B (2008) Social Work Research for Social Justice Basingstoke Palgrave Macmillan

NHS Health Scotland (2017) Evaluation of minimum unit pricing http://www.healthscotland.scot/health-topics/alcohol/evaluation-of-minimum-unit-pricing [Accessed 01-08-2017]

Neale, J; Black, L; Getty, M; Hogan, C; Lennon, P; Lora, C; McDonald, R; Strang, J; Tompkins, C; Usher, J, Villa, G; and A, Wylie (2017): Paying participants in addiction research: is cash king?, Journal of Substance Use Advanced Online Access http://dx.doi.org/10.1080/14659891.2016.1259367 [Accessed 01-08-2017].

Orford, J (2008) Asking the right questions in the right way: the need for a shift in research on psychological treatments for addiction Addiction, Volume 103, Number 6, pp875-85 Reason, P and Bradbury H (Eds.) (2001) The Handbook of Action Research. London, UK; Thousand Oaks, CA: Sage 
Sandberg, S. (2008) 'Black drug dealers in a white welfare state: Cannabis dealing and street capital in Norway', British Journal of Criminology, 48(5), pp. 604-619.

Tedmanson, D (2016) Ngapartji Ngapartji - Narratives of Reciprocity in 'Yarning Up' Participatory Research in Bryant, L. ed (2016) Critical and Creative Research Methodologies in Social Work, Routledge London (75-92).

Tolich, M. (2004) Internal Confidentiality: When Confidentiality Assurances Fail Relational Informants Qualitative Sociology 27(1): 101-106.

Voorberg, W. H.; Bekkers, V. J. J. M and Tummers, L.G.(2015) A Systematic Review of Co-Creation and Co-Production: Embarking on the social innovation journey, Public Management Review, 17(9), 1333-1357.

Whyte, W.F (1993) Street Corner Society: The Social Structure of an Italian Slum (4 ${ }^{\text {th }}$ edn) Chicago, University of Chicago Press. 


\begin{tabular}{|c|c|c|}
\hline \multicolumn{2}{|l|}{ Stages } & \\
\hline \multirow[t]{4}{*}{ Early and Formative } & $\mathrm{A}$ & $\begin{array}{l}\text { Agreeing scope of project and initial starting points } \\
\text { (Including resources and research bids) }\end{array}$ \\
\hline & $\mathrm{B}$ & $\begin{array}{l}\text { Recruiting PAIs } \\
\text { (Within inception fora and beyond where necessary) }\end{array}$ \\
\hline & $\mathrm{C}$ & $\begin{array}{l}\text { Broad agreement on research question and preferred } \\
\text { methods }\end{array}$ \\
\hline & $*$ & Ethics \\
\hline \multirow[t]{6}{*}{ Of Data } & $\mathrm{D}$ & $\begin{array}{l}\text { Developing detail of data collection methods } \\
\text { (including PAI training sessions) }\end{array}$ \\
\hline & $\mathrm{E}$ & Piloting \\
\hline & $\mathrm{F}$ & Revising data collection skills and tools \\
\hline & $\mathrm{G}$ & Respondent service user recruitment \\
\hline & $\mathrm{H}$ & Data collection and analysis \\
\hline & I & $\begin{array}{l}\text { (ongoing training and support to PAI from } \\
\text { experienced team members) }\end{array}$ \\
\hline \multirow[t]{4}{*}{ End Games and Impact } & $\mathrm{K}$ & Output Production \\
\hline & $\mathrm{L}$ & Dissemination \\
\hline & $*$ & $\begin{array}{l}\text { Commissioning, policy, organisational and service } \\
\text { provision change }\end{array}$ \\
\hline & $\mathrm{M}$ & (Next project) \\
\hline
\end{tabular}




\title{
$\underline{\text { Participatory Action Research (PAR) Research - Critical methodological considerations }}$
}

Authors

Dr. Wulf Livingston - Glyndwr University

Andrew Perkins - Figure 8 Consultancy Services Ltd.

Correspondence address - Wulf Livingston, Glyndwr University, School of Life and Social Sciences, PP13, Plas Coch Campus, Mold Road, Wrexham, Wales, LL11 2AW.

W.livingston@glyndwr.ac.uk

\begin{abstract}
Purpose: The purpose of this paper is to explore a range of key deliberations with regards to adopting Participatory Action Research (PAR) and Privileged Access Interviewer (PAI) approaches and methodologies within research on substance use

Design/methodology/approach: This paper is a reflective piece, it adopts a mixture of applied practice and theory considerations. These conceptualisations capture what are still relatively early understandings and uses of such methodologies, acquired across several decades of research and service provision experiences. The paper is structured around some of the sequences of the research process and as such provides a broad framework for such approaches.
\end{abstract}

Findings: PAR and PAI approaches utilise several key theoretical considerations. There are many critical issues associated with adopting these approaches, including those of ethics, funding, involvement, language, resources and support. Three key principle reasons (moral, political and research based), help explain why we should see more adoption of such approaches in substance use related research.

Research limitations/implications: This paper represents author views which are by their nature very subjective.

Practical implications: Implementation of the key considerations highlighted within this paper can lead to an active adoption of PAR and PAI methodologies within alcohol and drug research. Increasing the use of such methodologies will allow commissioners, researchers and 
service providers to develop a more nuanced understanding of the experiences of and responses to alcohol and drug use.

Originality/value: This paper captures critical conversations at a time of increased calls for service user involvement across all aspects of alcohol and other drug provision, including evaluation and research.

Key Words: Alcohol and Drugs, Involvement, Participatory Action Research, Research Methodologies, Substance Use

\section{Introduction}

This paper is based explicitly on the current views of its named authors. However, like all research papers, it builds upon previous experiences and projects (for example Biskin et al 2013, Livingston et al 2011), and previous writing (Livingston 2016, 2017). Therefore, much of what is offered is the co-production of a range of other actors who have clearly shaped its formulation. Given its nature, it would be inappropriate to not start by stating, that this paper is the consequence of all the generous sharing by and with all those we have worked with across numerous years in research and service provision. We are grateful to them for educating us, and as such we feel advocates rather than originators of the sentiments contained within this paper.

Participant Action Research (PAR) combines two separate research concepts:

- Participation - active involvement of 'subjects' in the research process; and

- Action - defining social problems and solving them.

It sits within a spectrum of what is considered patient, public or service user involvement. The movement to increased participation is often concentrated on provision and receipt of health and social care services, but also includes research into the effectiveness of services too (Brett et al 2014, Voorberg 2015). An early defining model of this spectrum was Arnstein's (1969) ladder of citizen participation, which suggested a full spectrum from manipulation to citizen control. In research terms, we might suggest some of the positions along the spectrum as:

- Non-Participation (manipulation) - service users partake purely as respondents from whom data is collected. 
- Degrees of moderate involvement - consultation or involvement in steering groups only.

- Significant involvement - delegated and designated roles within the research as researchers.

- Participatory Research - involved in the need for and commissioning of research, and/or as full team members from research bid through to final report.

The two concepts of PAR bring different elements and understanding to the research process. Firstly:

Participatory - this is what Gilbert (2008) refers to as doing with and for, rather than on others. It is thus concerned with definitions of expertise and knowledge and who controls these. It comes with what Humphries (2008) identifies as having several principles:

- a bottom up approach with a focus on locally defined priorities, processes and perspectives;

- striving for equalising power among researchers and researched;

- a process characterised by a genuine dialogue between researcher and researched;

- control over definition of problems, methods, analysis and actions is with those most affected by the study;

- the emphasis is on processes as much as on outcomes; and

- the role of the researcher is one of facilitator and catalyst rather than director.

Secondly:

Action - proposes that action researcher and members of a social setting collaborate in the understanding of a problem and in the development of a solution based on this understanding (Bryman 2008). This is supported by an emphasis on:

- nonintrusive collaboration (including ownership of the project by the group);

- mutual trust and genuine respect;

- solidarity (all humanity is connected by a common journey and shared destiny);

- mutuality and equality (everyone's interests are important);

- a focus on process (informal interaction that goes beyond a detached working relationship and respects others' cultures); and

- language as an expression of culture and power. 
Action research seeks intended consequences and expects elements of change to be experienced by all. It pursues to overtly improve the social situation, with both explicit practical application and political activity. It can occur across several activities, for example: organisational change, community development, new projects, practitioner research and social injustice.

The overall approach can be summarised as concerning itself with 'People, Power and Praxis' (Gilbert 2008) where traditional academic researchers translate their role into one of facilitating the goals of their co-researchers. Carey (2010) echoes these sentiments, in which three key considerations are raised: practical impediments, ethical implications and political dilemmas. He goes onto caution that there are possibilities that participation in research can mirror some of the current preoccupations in wider policy and provision, where participation may be encouraged or increased but not necessarily be successful in addressing the power dynamics; and may even exasperate them.

Privileged Access Interviewers (PAI) is a term that best captures why such methods are especially well suited for research inquiries into areas of activity and with people in experiences that are subject to societal marginalisation and often referred to as "hard to reach'. These include those of substance use. The approach is political apposite where there is a need to reach into certain populations, who are perhaps not readily captured by traditional research methodology. There are distinct overlaps with the ethnographic approaches drawn from social anthropology (Fine and Hancock 2017), and the essential role of those with access, as established through Whyte's (1993) seminal text and his relationship with Doc. Ennis and Wykes (2013) concluded that such involvement of service users in the research process enabled greater levels of recruitment to projects. Further, participatory approaches (i.e. those emphasising what can be considered as co-production), have a resonance and value in understanding the experiences of marginalised populations (Tedmanson 2016).

The principles of these approaches can, as most research techniques can, be applied to a range of design, data collection and analysis methods. This said, there is to some degree an inherent bias towards the subjective rather than the objective. Thus, many articulate for the use of an extensive range of qualitative written, visual and textual data collection methods (Bryant 2016), to compliment the traditional dominant paradigm for random control trials, statistics and surveys. 
Within these discourses, the use of terminology implies ontological and methodological positions. The ethical, morale and methodological implications of this language are explored further on, but for consistency this paper, from hereon in, refers to those whom are actively involved in the research as participants and those who contribute or offer data examples as respondents. For expediency, it adopts substance use to capture the diversity of both 'substances' (alcohol, illicit, legal and illegal drugs) and 'use' (dependency, excessive, harmful, hazardous and recreational).

\section{Starting Points}

These approaches have several assumptions (or givens) that might be considered as preexisting contextual considerations.

Whilst the idea that a group of service users will just wander up to a university and ask for assistance in a research project might sound like the optimum and theoretical starting point (and indeed does occasionally happen), it is likely (and should be likely if co-production is indeed an increasingly wider commissioning, policy and service provision norm) that ideas are generated from within existing involvement activity. This could or should happen in substance use organisations or fora where meaningful participation is already well established with regards to other business or activities. This methodology therefore demands that initial conversations have been reciprocal and not unduly led by agencies/researchers to meet their own agendas. Thus, involvement prior to design or research bid application, moves research further along the possible spectrum of participation.

From here it is appropriate to have one or two dedicated conversations/meetings that scope out a project. These might well want to involve others not deemed as participants, as well as early project initiators. This is important to ensure that the research is supported, welcomed and has a good level of stakeholder engagement and involvement from the start. These early conversations need to include explicit exploration of ethical and resourcing issues. Such solid foundations of shared understanding are important, to help ease future resistance, when goals are directed towards political change.

It is likely, if not desirable or expected, that such a stage maybe the precursor to a formal funding application. Although as outlined below, acquiring funding is not without its difficulties. Ideally in such instances, applications are made with participants rather than on their behalf. 
It feels important to emphasise that, in these early meetings, service user and participant voice is strong and not of a singular or representative type. Indeed, some might argue they need to be the majority for it to be truly participative, and the involvement of other professionals and researchers is for consultation.

\section{Identifying and recruiting participants}

In many instances those individuals involved in the initial and scoping conversations may well be those identified as the participants or PAIs. It feels important that potential participation is invited across many roles and responding to a variety of interest and skills, such as: project advisories or consultants, full blown participants, advertisers, recruiters, respondents and supporters. While initial conversations may generate enough involvement, in many instances there is likely to be the need for further recruitment - especially for PAI type projects. This will need to follow a purposeful sampling methodology, using a combination of targeted advertisement (with active consideration given to mobile and social media methods) and snowballing through existing networks and relationships.

There comes a point in participatory methods, if this has not happened fully at inception, where any project needs to ensure its direction is highly participant led. At this juncture, the research team (PAI and supporting academics) need to possibly withdraw from wider stakeholder discussions and begin to enable an approach which is very much service led, rather than informed. The role of the (academic) researcher here, is to facilitate discussions and understanding among the participants, and support them to agree upon the specific methods of inquiry.

Substance use research has the possibility to see co-production beyond the service user group and partnership could see carers, families, practitioners or students become the participant population.

\section{Language and Terminology}

Early formulations of this paper, were borne out of and reflect struggles with language. Much research literature frequently refers to participants. When in the context of an understanding of genuine partnership involvement, what is being referred to is, those from whom data has been collected. The use of participant almost seems a hangover of a subject involved in a controlled experiment, rather than any sense of any co-production; the exceptions perhaps being those engaged in ethnography or discourse analysis. For us, the ambiguity and 
confusion was cleared by choosing to be firm in distinguishing between those from whom we collect data (respondents), and those who actively participate in the other aspects of the research process (participants).

While such deliberations, may appear of semantics, they are in fact rooted in issues of power. At the heart of them lies a transparent declaration of whether researchers are distinct from (expert and controlling), or sharing in the same human experience (indeed, most alcohol researchers are drinkers). The latter position begins to ask fundamental questions of whether one truth or measurable actuality exists, rather than being a construct of any given (research) process. Furthermore, it raises questions of who is the expert and in what capacity. It also suggests the equal validity of all research methods, rather than supporting a hierarchy of the traditional or dominant. Finally, it implies the assumption of a sharing of access to resources and rewards from the research process.

\section{Ethics}

As research, normal ethical considerations and processes must be accounted for. Projects will need to undertake appropriate due research ethics processes. It is possible that where ethics boards are predominantly used to, or dominated by traditional positivist and experimental type research approaches, that understanding of, and support for, PAR approaches maybe more limited. However, it is our experience that ethical approval is gained when attention is paid to specific key considerations; notably issues of boundaries and researcher confidence.

These approaches have a resonance with ethnography, which in turn helps to inform the management (or not) of boundary issues. Researchers are considered, if not expected, to be an active part of the community. Indeed, it is the opposite of aloof non-participatory observation which, in terms of the politics of involvement, might be considered a more exploitative and unethical approach. Working within discreet populations, as accessed via a PAI, challenges the boundaries of what is considered normal confidentiality for other research methodologies. Tolich (2004) acknowledges that an overt understanding of this helps accept the limits in the principles of confidentiality. Insiders are more likely to recognise what other insiders have said. He concludes that internal confidentiality is distinct from external confidentiality, and suggests the assurances for protection against identification is with those who were not subjects of the research, rather than within the discreet population cohort or community. 
Because the methodology described here is a) not as deterministic or predictable in its course of action and b) process orientated, then the ethical requirement is for confidence in the researcher and/or research team (as much as the prescription of methods) and the successful management of what can appear as more fluid boundaries between the researcher and the researched. Ethics committee confidence, is often, as with other methods and about relevant prior experience of the researcher. One of the authors (as a registered social worker) has found it is important to stress equally the oversight of practice and research ethics. Thus, the process of being held accountable to a professional regulatory body, compliment those of research ethics, as might a social work qualification compliment a $\mathrm{PhD}$. This is because many of the research ethics issues are foremost practice dilemmas.

As might be expected, there is also regular concern raised about the use of payments for participants in this area of research, and possibilities of monies being spent on alcohol or drugs. The ethical concerns often fall into two considerations: those of undue incentive to participate, and/or payment leading to risk of harm. However, many researchers have now clearly articulated why genuine participation (issues of power) require this group of users to be treated the same as others and that payment is a requisite (Fry et al 2006, Neale et al 2017, Sandberg 2008). The counter argument, therefore stems around payments as justifiable and fair reimbursement for time given and expenses occurred. The usual compromise is to provide individuals with high street shopping vouchers that cannot be exchanged for alcohol or cigarettes. Fry et al (2006) in their article conclude "...research payments are ethically acceptable in most circumstances of addictions research, but should be closely scrutinized in situations where these may exacerbate existing harms or create additional risks for participants and investigators" (p21). In extreme cases (i.e. street drug dealing or use of drugs by sex workers), then payment maybe the only way individuals can viably participate without loss of income earning time, and cash rather than any voucher system will be required (Sandberg 2008).

\section{Funding and research bids}

If a bid for a participatory project is to be made with clear evidence of involvement having informed it, then this involvement also needs funding. For traditional research, bid preparation activity, is part of the paid job role for academics. To ensure a parity and active involvement of others, it seems to be an important and logical consideration that some of the commissioning, policy and organisational fora (referred to above), is also able to create funds 
and resource capacity for appropriate involvement to inform potential research project starting points.

Even assuming this informed prior application involvement, one of the biggest barriers to getting such research projects off the ground, is often the successful acquisition of external funding. Research funds often sit in a competitive bid process, including blind peer review processes. These processes aspire to establish exactly what a research project is going to do, so how well detailed and predictable and/or reliable the methodology described is. These scoring methods often have a bias towards predictive/positivist experimental research over methods where determining the methodology is a part of the process and not fully determined prior to. Truly iterative and participatory approaches cannot provide such clarity before they have begun. In addition, and much like the ethics committee, the bids are assessed by panels of experts whose own experiences and understanding lie with controlled experiments, quantitative surveys and statistical modelling rather than qualitative involvement. Thus, there is a more inherent bias where participatory action approaches are neither understood, nor valued by those responsible for making such judgements. Typical of those sentiments is the following example that this author received from a recent 'friendly' reviewer post an award being made:

The use of participant researchers looks innovatory but pretty risky, and the sample size is very small. A small and potentially contentious methodology ... is unlikely to make a big difference to conclusions even if it worked.

This situation was recently acknowledged at the 2017 Alcohol Research UK Annual Conference, that in part has led to this special edition ${ }^{1}$.

\section{Data collection and analysis}

Whilst all forms of data collection tools can be used within participatory approaches, there is often an inherent leaning towards the intrapersonal and relationship based inquires, so frequently qualitative methodology. Whilst this may regularly be done through focus groups and interviews with schedules and a range of semi-structured questions, participatory approaches also lend themselves to the use of arts and other creative data capture approaches (Bryant 2016). Iterative approaches (typical of highly qualitative methods to data collection and analysis, whereby the experience of one element feeds into and refines the next) feel

\footnotetext{
${ }^{1}$ http://alcoholresearchuk.org/news/alcohol-research-uk-annual-conference-2017/
} 
highly resonant with involvement approaches that are seeking to develop collective understanding and inform change.

It is possible that PAIs will at these junctures require some formative input from the academics or others within the research team. Thus, some of the research team need at times to translate facilitator into educator roles. So, the stage here is the sharing of expertise and knowledge about research techniques. Active consideration must be given to how material often used in other classroom settings, might need to be adapted for different audiences and learning needs.

It can be useful for PAIs to conduct the data collection method on each other. This provides: a) safe space to practice and receive feedback on, and refine techniques; and b) potential initial data that can be used within the wider data collection set. It might be that where data has been collected via film or audio, that the experienced researcher facilitator also watches and listens to the data, to provide supportive feedback to PAIs. Similarly, methods of analysis might need to be explained or adapted to suit the needs of the PAI population. Consideration needs to be given to how best to support PAI involvement in analysis, so without assumption about access to and competence in IT. Some PAIs will want to be actively involved in the use of say SPSS or NVivo, but for others, a paper based or aural process maybe more suitable. Added reliability can occur with dual analysis approaches and then comparison of interpretations, so one approach for some PAIs and then a complimentary or additional one from the experienced or academic team members. An active but supportive role of experienced researchers within the cohort, can act as an additional process of quality assurance.

Recruitment of respondents, is likely to follow the same purposeful sampling methodology, using a combination of targeted advertisement (with active consideration given to mobile and social media methods) and snowballing through the existing networks and relationships used in PAI recruitment. Research that utilises peer and recovery groups means that individuals are known to each other within the community. Reflexive considerations of insider research approaches are required. Within this, identification of what proximity to potential respondents the PAIs are should be undertaken and used as inclusion or exclusion criteria; or passed onto another PAI within the project.

As PAIs spread out into the respective community and collect data, the experienced members of the team must be available for ongoing mentoring and support. 


\section{Post data considerations}

Like other research methods, it is good to find a process by which emerging outcomes can be 'tested' out with those most likely to be impacted; and their responses to this, can shape any final conclusions. This could include taking initial findings back to any initiating fora or project advisory group. Active recovery communities, are also likely to provide on-going spaces where PAIs can test and make sense of emerging findings and conclusions.

It is likely that commissioners of research will want to see traditional 'research reports'. Further, any academics involved will want to, and be under pressure to, publish within peer review journals. In both these regards it is important that a) the opportunity to participate in 'writing up' is extended to PAIs, and b) irrespective of their involvement in the writing up, they are fully acknowledged (with consent) as co-authors. However, some projects, some groups etc., may also identify other non-written ways of wanting to present research findings. The adoption of these seems important, especially when considering research as both involved and action orientated. The change implied in action is likely to come from the widest of dissemination approaches.

Part of an action orientated methodology, which has process as important as outcomes, and considers outcomes for all, is about establishing sustainable PAI populations to then a) advise and support commissioning of future research, b) get involved in other projects, and c) act as peer mentors for future PAIs.

\section{Applied Framework}

It is possible to synthesise these considerations into a broad or proximate framework (model) comprising multiple stages.

Table 1: Model of stages of Participant Action Research approach

\section{Insert table 1 here}

Stages are iterative and overlap.

* These stages involve processes and organisations that are possibly external to the research team, so not fully within projects influence.

\section{Applied considerations}


This paper has been influenced by a diversity of previous and on-going research projects. However, given the considerations described, it has equally (if not more so) been informed by: many unsuccessful research bids, policy conversations, recovery group deliberations and reflections on the limitations of other research (including ours). This final section offers some of the learning we have acquired through these experiences.

PAR projects require a lot of (and at times freely given) energy and time, to ensure they are successful and sustainable. Several of the recent projects we have contributed to, have come out of long-term prior existing relationships. In other words, we have been actively involved in those fora discussed in the earlier part of this paper. This requires the academic researcher to spend time out and about in the community. Notably, we have been active members of recovery group networks and partnerships, often giving skills and time just like any other volunteer. Successful bids and projects are far more likely to come from already established and trusting relationships. We have, as is consistent with other research approaches, spent time doing early, small and unfunded pilot formulations. There is a need to continue, especially in economic climates where organisations and universities increasingly seek to restrict activities to those associated with computerised workload management agendas, for researchers to articulate that such time spent is necessary and valuable - especially as this is required to be off site. There is scope here to use organisational good citizenship or social good agendas to help meet these goals.

That participatory research, especially that involving action (for change), is as much a political, as it is research activity has therefore been one of the earliest and consistent messages. Biskin et al (2013) identify how even the simple task of social work students being encouraged in the classroom to expect service user and carer involvement, then meet resistance when wanting to account for whether they actually experience such in practice through a research project. So, whilst the service user involvement agenda is well established in substance use policy and provision agendas, it has yet to fully impact on the research world. Service user involvement has tended to primarily focus on the active participation of 'users' within treatment policy and provision agendas, rather than all users and ex users and including evaluation and research activities. In a recently completed review of the Welsh Governments 10-year alcohol (and drug) strategy, there was no PAR material amongst the relevant data sets and evaluations (Livingston et al 2017). 
PAR and PAI approaches require inclusivity, and measured risk taking, if they are to succeed in being different and provide alternative explanations. We have had expressed to us concerns about PAIs interviewing those who are still actively using and exposing their own vulnerability to relapse (which assumes that PAIs are abstinent - which need not necessarily be the case) and how rigid (or not) any criteria for PAIs needs to be. This in turn, raises concerns for us, about whether researchers could be tempted into using PAI recruitment methodologies which are too strict, or too controlling, unless they themselves are prepared to take a few risks. PAR research ought to have the capacity to involve the whole spectrum of use or not. It is by its nature risk taking rather than risk adverse. When working with those in recovery as PAIs, it seems important to entrust to their already successfully developed notions of management and networks of support, rather than impose secondary researcher led frameworks. In fact, this makes us think that the success of PAI methodologies is also shaped by the characteristics of the research facilitator as it those of the PAIs recruited. Inclusivity and risk taking is thus required by those; commissioning, evaluating, overseeing and undertaking research. This seems to be only a fair and reciprocal to the risk we ask of others in entrusting and sharing their experiences with us.

It feels as if over the last decade that the tide is finally turning. Indeed, the ARUK conference that is the precursor and inspiration for this special edition, is one obvious marker in this evolutionary journey. The explicit requirement to demonstrate involvement now appears to be a regular element of research bid application process requirements. Indeed, we have had more bid success of late (albeit maybe it is just that we have got a bit better at that bit). Notably, and very recently, an acceptance of the validity of the contribution these methods can make to enhance a complexity of methods in understanding national policy, has been acknowledged by Health Scotland in its commissioning of participatory methods as one of the streams within the evaluation of the impact of minimum unit pricing on harmful drinkers (NHS Health Scotland 2017).

\section{Concluding discussion}

At one level, there is nothing revolutionary in the principles of PAR or the methodological considerations explored within this paper. In part, they just feel like good conscious and reflexive research practices. However, at another level they seek to comprehensively resonate with aspirations for greater service user involvement in policy, practice and research activities. They have a feel of the ideological, a set of best laid aspirations and intentions. In 
this sense, the revolutionary comes from trying to meet as many of the ambitions as possible within each project, while contributing to an overall picture of change and challenge to an existing order that places expert led controlling experimental research at the pinnacle of perceived research hierarchies.

It is possible to reduce these complex discussions into three clear reasons why we should do and see more PAR/PAI research within alcohol and other drug studies. Firstly, this feels like a moral imperative. It is just the right thing to do. There has been an explosion in service user involvement in policy and service provision for substance use, and this needs to be matched by those researching such. Substances are widely consumed in society, including by researchers, the boundaries between an 'us and them' population often maintained by researchers, in this instance seems particularly false. It maybe that we need to turn the traditional research ethics preoccupation with protecting the vulnerable on its head, and into one of entrust, empower and respect. Secondly, this is a political issue. It raises fundamental questions of ontology and epistemology. A challenge to a dominant and vested interest about who does research and how. It asks questions of who is the 'expert'. It asks that research has an impact beyond the vested interest of the academic career and the research frameworks that academic institutions are increasingly judged by. Finally, and this is the purpose of research, new methodologies help create new understanding. There is more than one way to know how. It is a direct and appropriate response to Orford's (2008) seminal paper that argued for substance use research to move beyond its preoccupation with the randomised control trial. These are methodologies that enable us to gain a greater insight into the nature of experiences and relationships that are at the core of understanding why individuals develop difficulties regarding their substance use and how they might best be supported in developing healthier lifestyles.

It is possible to see two overlapping 'new' waves at work here. Where research has accepted the role of the sociological and qualitative to compliment the experimental and quantitative, it has yet to fully embrace moves to take this outside of the academy. Similarly, where substance use has embraced harm reduction and whole population agendas as a response to narrow disease model understandings, it has yet to fully reconcile itself with some of the newer debates and understanding about recovery and the increased control and involvement of those most affected. This paper simply seeks to contribute to these journeys.

\section{References}


Arnstein, S. R. (1969) "A Ladder of Citizen Participation," JAIP, 35(4). 216-224

Biskin, S. Barcroft, V. Livingston, W. and Snape, S (2013). Exploring service user and care involvement on a social work degree programme, Social Work Education: The International Journal, 32(3), pp.301-316.

Bradbury, H., and Reason, P. (2003). Action research: An opportunity for revitalizing research purpose and practices. Qualitative Social Work, 2(2), 155-175

Brett, J., Staniszewska, S., Mockford, C., Herron-Marx, S., Hughes, J., Tysall, C. and Suleman, R. (2014), Mapping the impact of patient and public involvement on health and social care research: a systematic review. Health Expectations, 17(5): 637-650

Bryant, L. (2016) Introduction in Bryant, L. ed (2016) Critical and Creative Research Methodologies in Social Work, Routledge London (75-92).

Bryman, A. (2008) Social Research Methods Oxford, Oxford University Press.

Carey, M. (2010) Should I stay or should I go? Practical, ethical and political challenges to 'Service User' Participation within Social work research. Qualitative Social Work 10(2): 224-243.

Ennis and Wykes (2013) Impact of patient involvement in mental health research: longitudinal study The British Journal of Psychiatry 203: 381-386.

Fine, G. A and Hancock, B. H.(2017) The new ethnographer at work Qualitative Research 17(2): $260-268$.

Fry, C.: Hall, W; Ritter, A and Jenkinson, R (2006) The ethics of paying drug users the ethics of paying drug users who participate in research: a review and practical recommendations who participate in research: a review and practical recommendations. Journal of Empirical Research on Human Research Ethics,. 21-36.

Gilbert, N (2008) Researching Social Life London, Sage.

Humphries, B (2008) Social Work Research for Social Justice Basingstoke Palgrave Macmillan

Livingston W. (2016) Responding to Orford: Diverse methodological aspirations Alcohol Research UK Early Researcher Symposium, March 15th Birmingham 
http://www.fead.org.uk/video/dr-wulf-livingston-responding-to-orford-diversemethodological-aspirations/ [Accessed 01-08-2017]

Livingston, W (2017) Participatory Action Research (PAR) Research: Considerations for a qualitative methodological approach. Kettil Bruun Society: Symposium (Sheffield) June 5-9th (Paper available).

Livingston, W. Baker, M. Atkins, B and Jobber, S. (2011) 'A tale of the spontaneous emergence of a recovery group and the characteristics that are making it thrive: Exploring the politics and knowledge of recovery' The Journal of Groups in Addiction and Recovery 6(1), pp. 176-196.

Livingston, W; Perkins, A; McCarthy, T; Madoc-Jones, I; Wighton, S; Wilson, F and Nicholas, D (2017). Review of Working Together to Reduce Harm: Final Report (Due for publication September 2017).

NHS Health Scotland (2017) Evaluation of minimum unit pricing http://www.healthscotland.scot/health-topics/alcohol/evaluation-of-minimum-unit-pricing [Accessed 01-08-2017] Neale, J; Black, L; Getty, M; Hogan, C; Lennon, P; Lora, C; McDonald, R; Strang, J; Tompkins, C; Usher, J, Villa, G; and A, Wylie (2017): Paying participants in addiction research: is cash king?, Journal of Substance Use Advanced Online Access http://dx.doi.org/10.1080/14659891.2016.1259367 [Accessed 01-08-2017].

Orford, J (2008) Asking the right questions in the right way: the need for a shift in research on psychological treatments for addiction Addiction, Volume 103, Number 6, pp875-85 Reason, P and Bradbury H (Eds.) (2001) The Handbook of Action Research. London, UK; Thousand Oaks, CA: Sage

Sandberg, S. (2008) 'Black drug dealers in a white welfare state: Cannabis dealing and street capital in Norway', British Journal of Criminology, 48(5), pp. 604-619.

Tedmanson, D (2016) Ngapartji Ngapartji - Narratives of Reciprocity in 'Yarning Up' Participatory Research in Bryant, L. ed (2016) Critical and Creative Research Methodologies in Social Work, Routledge London (75-92). 
Tolich, M. (2004) Internal Confidentiality: When Confidentiality Assurances Fail Relational Informants Qualitative Sociology 27(1): 101-106.

Voorberg, W. H.; Bekkers, V. J. J. M and Tummers, L.G.(2015) A Systematic Review of Co-Creation and Co-Production: Embarking on the social innovation journey, Public

Management Review, 17(9), 1333-1357.

Whyte, W.F (1993) Street Corner Society: The Social Structure of an Italian Slum (4 ${ }^{\text {th }}$ edn) Chicago, University of Chicago Press. 
Drugs and Alcohol Today Article - Response to Reviewers.

We are grateful to both reviewers for the positive responses. We are in broad agreement with the observations and suggestions made, and that they would improve the overall articles submission. We have made minor amendments accordingly.

Reviewer: 1

Comments:

I felt there could be a fuller discussion of the ethics of reimbursements see e.g. Ritter, 2003; fry et al., 2006; or Neale et al., 2017.

While two of these sources were already cited, we have revisited the section and looked in particular at the issue of cash as opposed to vouchers

Difficulties of Funding - II wondered whether the authors had any suggestions to overcome this?

Some suggestions are embedded in the applied considerations

Post data considerations - I think the authors' ideas regarding PAl involvement in writing-up papers and especially co-authorship is novel and important.

See point below in regards to this paper and reviewer 2's comments

Needs proof reading for a sporadic and overuse of commas.

This has been attended to and each letter preceding deleted comma has been highlighted

\section{Reviewer: 2}

Would it be worth including a reference on page 5 line 42 when referring to '..some might argue they need to be the majority...'

\section{Added}

The second paragraph on page 7 looks a little one sided, the limitations of 'non-participatory research' are highlighted, perhaps briefly balancing this with the strengths of such an approach might help even this section up a little.

\section{Additional sentences added}

The description of the process of applying for research funds in the last paragraph on page 8 is good but would benefit from another supporting reference.

Reference added

Is it worth referring to the British Medical Journal approach ? the BMJ has adopted a requirement that all papers submitted state clearly how patients/service users have been actively involved.

This is has been noted in the applied considerations

It wasn't clear if the authors had consulted service users or involved them in writing this paper? there is a suggestion in the introduction that the writing is based on the authors experience working 
with such people over some time but given the arguments raised in this paper some explanation of how the authors approached this (or not) is needed.

The wording in the introduction has been clarified

A new paragraph added in post data considerations

The conclusion does bring together the main strands of the paper however the first of the three points referred to includes the issue of 'us and them' when referring to boundaries between researchers and service users - this is an interesting point which is only briefly explored in the main text when referring to researchers consuming alcohol, I think this line of thought is interesting and could be expanded a little in the main body of the paper.

Several additional sentences have been added/amended to reiterate this point in other sections e.eg confidentiality, language etc

I wonder if there is scope to tailor or at least more directly relate the points made directly to drugs and alcohol. A few examples are given but I suspect there is potential to make more explicit reference and links.

Where possible, within word count we have tried to make this more overt

\title{
Participatory Action Research (PAR) Research - Critical methodological considerations
}

Authors

Correspondence address -

\begin{abstract}
Purpose: The purpose of this paper is to explore a range of key deliberations with regards to adopting Participatory Action Research (PAR) and Privileged Access Interviewer (PAI) approaches and methodologies within research on substance use

Design/methodology/approach: This paper is a reflective piece, it adopts a mixture of applied practice and theory considerations. These conceptualisations capture what are still relatively early understandings and uses of such methodologies, acquired across several decades of research and service provision experiences. The paper is structured around some of the sequences of the research process and as such provides a broad framework for such approaches.
\end{abstract}


Findings: PAR and PAI approaches utilise several key theoretical considerations. There are many critical issues associated with adopting these approaches, including those of ethics, funding, involvement, language, resources and support. Three key principle reasons (moral, political and research based), help explain why we should see more adoption of such approaches in substance use related research.

Research limitations/implications: This paper represents author views which are by their nature very subjective.

Practical implications: Implementation of the key considerations highlighted within this paper can lead to an active adoption of PAR and PAI methodologies within alcohol and drug research. Increasing the use of such methodologies will allow commissioners, researchers and service providers to develop a more nuanced understanding of the experiences of and responses to alcohol and drug use.

Originality/value: This paper captures critical conversations at a time of increased calls for service user involvement across all aspects of alcohol and other drug provision, including evaluation and research.

Key Words: Alcohol and Drugs, Involvement, Participatory Action Research, Research Methodologies, Substance Use

\section{Introduction}

This paper is explicitly the current views of its named authors. However, like all research papers, it builds upon previous experiences and projects (for example Biskin et al 2013, Author et al 2011) and previous writing (Author 2016, 2017). Therefore, much of what is offered emanates from co-production activities with other actors which have influenced its formulation. Given its nature, it would be inappropriate to not start by stating that this paper is the consequence of all the generous sharing by and with all those we have worked with across numerous years in research and service provision. We are grateful to them for educating us and as such we feel advocates rather than originators of the sentiments contained within this paper.

Participant Action Research (PAR) combines two separate research concepts:

- Participation - active involvement of 'subjects' in the research process; and

- Action - defining social problems and solving them. 
It sits within a spectrum of what is considered patient, public or service user involvement. The movement to increased participation is often concentrated on provision and receipt of health and social care services, but also includes research into the effectiveness of services too (Brett et al 2014, Voorberg 2015). An early defining model of this spectrum was Arnstein's (1969) ladder of citizen participation which suggested a full spectrum from manipulation to citizen control. In research terms we might suggest some of the positions along the spectrum as:

- Non-Participation (manipulation) - service users partake purely as respondents from whom data is collected.

- Degrees of moderate involvement - consultation or involvement in steering groups only.

- Significant involvement - delegated and designated roles within the research as researchers.

- Participatory Research - involved in the need for and commissioning of research, and/or as full team members from research bid through to final report.

The two concepts of PAR bring different elements and understanding to the research process, including that of alcohol and drugs.

Firstly:

Participatory - this is what Gilbert (2008) refers to as doing with and for, rather than on others. It is thus concerned with definitions of expertise and knowledge and who controls these. It comes with what Humphries (2008) identifies as having several principles:

- a bottom up approach with a focus on locally defined priorities, processes and perspectives;

- striving for equalising power among researchers and researched;

- a process characterised by a genuine dialogue between researcher and researched;

- control over definition of problems, methods, analysis and actions is with those most affected by the study;

- the emphasis is on processes as much as on outcomes; and

- the role of the researcher is one of facilitator and catalyst rather than director.

Secondly: 
Action - proposes that action researcher and members of a social setting collaborate in the understanding of a problem and in the development of a solution based on this understanding (Bryman 2008). This is supported by an emphasis on:

- nonintrusive collaboration (including ownership of the project by the group);

- mutual trust and genuine respect;

- solidarity (all humanity is connected by a common journey and shared destiny);

- mutuality and equality (everyone's interests are important);

- a focus on process (informal interaction that goes beyond a detached working relationship and respects others' cultures); and

- language as an expression of culture and power.

Action research seeks intended consequences and expects elements of change to be experienced by all. It pursues to overtly improve the social situation with explicit practical application and political activity. It can occur across several activities, for example: organisational change, community development, new projects, practitioner research and social injustice.

The overall approach can be summarised as concerning itself with 'People, Power and Praxis' (Gilbert 2008) where traditional academic researchers translate their role into one of facilitating the goals of their co-researchers. Carey (2010) echoes these sentiments in which three key considerations are raised: practical impediments, ethical implications and political dilemmas. He goes onto caution that there are possibilities that participation in research can mirror some of the current preoccupations in wider policy and provision, where participation may be encouraged or increased but not necessarily be successful in addressing the power dynamics; and may even exasperate them.

Privileged Access Interviewers (PAI) is a term that best captures why such methods are especially well suited for research inquiries into areas of activity and with people in experiences that are subject to societal marginalisation and often referred to as 'hard to reach'. These include those of substance use. The approach is political apposite where there is a need to reach into certain populations who are perhaps not readily captured by traditional research methodology. There are distinct overlaps with the ethnographic approaches drawn from social anthropology (Fine and Hancock 2017), and the essential role of those with access as established through Whyte's (1993) seminal text and his relationship with Doc. Ennis and Wykes (2013) concluded that such involvement of service users in the research 
process enabled greater levels of recruitment to projects. Further, participatory approaches (i.e. those emphasising what can be considered as co-production) have a resonance and value in understanding the experiences of marginalised populations (Tedmanson 2016), including alcohol and drug use.

The principles of these approaches like most research techniques be applied to a range of design, data collection and analysis methods. This said, there is to some degree an inherent bias towards the subjective rather than the objective. Thus, many articulate for the use of an extensive range of qualitative written, visual and textual data collection methods (Bryant 2016) to compliment the traditional dominant paradigm for random control trials, statistics and surveys.

Within these discourses the use of terminology implies ontological and methodological positions. The ethical, morale and methodological implications of this language are explored further on; but for consistency this paper, from hereon in, refers to those whom are actively involved in the research as participants and those who contribute or offer data examples as respondents. For expediency it adopts substance use to capture the diversity of both 'substances' (alcohol, illicit, legal and illegal drugs) and 'use' (dependency, excessive, harmful, hazardous and recreational).

\section{Starting Points}

These approaches have several assumptions (or givens) that might be considered as preexisting contextual considerations.

Whilst the idea that a group of alcohol and drug service users will just wander up to a university and ask for assistance in a research project might sound like the optimum and theoretical starting point (and indeed does occasionally happen), it is likely (and should be likely if co-production is indeed an increasingly wider commissioning, policy and service provision norm) that ideas are generated from within existing involvement activity. This could or should happen in substance use organisations or fora where meaningful participation is already well established with regards to other business or activities. This methodology therefore demands that initial conversations have been reciprocal and not unduly led by agencies/researchers to meet their own agendas. Thus, involvement prior to design or research bid application moves research further along the possible spectrum of participation. 
From here it is appropriate to have one or two dedicated conversations/meetings that scope out a project. These might well want to involve others not deemed as participants as well as early project initiators. This is important to ensure that the research is supported, welcomed and has a good level of stakeholder engagement and involvement from the start. These early conversations need to include explicit exploration of ethical and resourcing issues. Such solid foundations of shared understanding are important to help ease future resistance when goals are directed towards political change.

It is likely, if not desirable or expected, that such a stage maybe the precursor to a formal funding application. Although, as outlined below, acquiring funding is not without its difficulties. Ideally in such instances applications are made with participants rather than on their behalf.

It feels important to emphasise that, in these early meetings, service user and participant voice is strong and not of a singular or representative type. Indeed, some might argue they need to be the majority for it to be truly participative, and the involvement of other professionals and researchers is for consultation (McLaughlin 2010).

\section{Identifying and recruiting participants}

In many instances those individuals involved in the initial and scoping conversations may well be those identified as the participants or PAIs. It feels important that potential participation is invited across many roles and responding to a variety of interest and skills, such as: project advisories or consultants, full blown participants, advertisers, recruiters, respondents and supporters. While initial conversations may generate enough involvement, in many instances there is likely to be the need for further recruitment - especially for PAI type projects. This will need to follow a purposeful sampling methodology, using a combination of targeted advertisement (with active consideration given to mobile and social media methods) and snowballing through existing substance use networks, relationships and recovery organisations.

There comes a point in participatory methods, if this has not happened fully at inception, where any project needs to ensure its direction is highly participant led. At this juncture the research team (PAI and supporting academics) need to possibly withdraw from wider stakeholder discussions and begin to enable an approach which is very much service led, rather than informed. The role of the (academic) researcher here is to facilitate discussions 
and understanding among the participants, and support them to agree upon the specific methods of inquiry.

Substance use research has the possibility to see co-production beyond the service user group and partnership could see carers, families, practitioners or students become the participant population.

\section{Language and Terminology}

Early formulations of this paper were borne out of and reflect struggles with language. Much research literature frequently refers to participants. When in the context of an understanding of genuine partnership involvement, what is being referred to is those from whom data has been collected. The use of participant almost seems a hangover of a subject involved in a controlled experiment, rather than any sense of any co-production; the exceptions perhaps being those engaged in ethnography or discourse analysis. For us, the ambiguity and confusion were cleared by choosing to be firm in distinguishing between those from whom we collect data (respondents), and those who actively participate in the other aspects of the research process (participants).

While such deliberations may appear of semantics, they are in fact rooted in issues of power. They challenge perceptions of 'us and them' populations. At the heart of them lies a transparent declaration of whether researchers are distinct from (expert and controlling), or sharing in the same human experience (indeed most alcohol researchers are drinkers). The latter position begins to ask fundamental questions of whether one truth or measurable actuality exists, rather than being a construct of any given (research) process. Furthermore, it raises questions of who is the expert and in what capacity. It also suggests the equal validity of all research methods, rather than supporting a hierarchy of the traditional or dominant. Finally, it implies the assumption of a sharing of access to resources and rewards from the research process.

\section{Ethics}

As research, normal ethical considerations and processes must be accounted for. Projects will need to undertake appropriate due research ethics processes. It is possible that where ethics boards are predominantly used to, or dominated by traditional positivist and experimental type research approaches, that understanding of (and support for) PAR approaches maybe 
more limited. However, it is our experience that ethical approval is gained when attention is paid to specific key considerations; notably issues of boundaries and researcher confidence.

These approaches have a resonance with ethnography, which in turn helps to inform the management (or not) of boundary issues. Researchers are considered, if not expected, to be an active part of the community. Indeed, it is the opposite of aloof non-participatory observation which, in terms of the politics of involvement, might be considered a more exploitative and unethical approach. Active researcher participation offers the opportunity of more realistic, transparent and trustworthy interactions. It works with continuums of populations and communities, rather than suggestions of 'us and them' populations. Working within discreet populations (as accessed via a PAI) challenges the boundaries of what is considered normal confidentiality for other research methodologies. Tolich (2004) acknowledges that an overt understanding of this helps accept the limits in the principles of confidentiality. Insiders are more likely to recognise what other insiders have said. He concludes that internal confidentiality is distinct from external confidentiality and suggests the assurances for protection against identification is with those who were not subjects of the research, rather than within the discreet population cohort or community.

Because the methodology described here is a) not as deterministic or predictable in its course of action and b) process orientated, then the ethical requirement is for confidence in the researcher and/or research team (as much as the prescription of methods) and the successful management of what can appear as more fluid boundaries between the researcher and the researched. Ethics committee confidence is often, as with other methods, about any relevant prior experience of the researcher. One of the authors (as a registered social worker) has found it is important to stress equally the oversight of practice and research ethics. Thus, the process of being held accountable to a professional regulatory body compliment those of research ethics, as might a social work qualification compliment a $\mathrm{PhD}$. This is because many of the research ethics issues are foremost practice dilemmas.

As might be expected, there is also regular concern raised about the use of payments for participants in this area of research. The ethical concerns often fall into two considerations: those of undue incentive to participate (Ritter et al 2003), and/or payment leading to risk of harm, notably with the possibilities of monies being spent on substances. However, many researchers have now clearly articulated why genuine participation (issues of power) require this group of users to be treated the same as others and that payment is a requisite (Fry et al 
2006, Neale et al 2017, Sandberg 2008). Fry et al (2006) in their article conclude “...research payments are ethically acceptable in most circumstances of addictions research, but should be closely scrutinized in situations where these may exacerbate existing harms or create additional risks for participants and investigators" (p21). This counter argument therefore stems around payments as justifiable and fair reimbursement for time given and expenses occurred. The concerns about cash being spent on substances is usually compromised by providing individuals with high street shopping vouchers that cannot be exchanged for alcohol or cigarettes. Participants in research studies have expressed that the use of vouchers can present implied lack of trust or feel paternalistic and may even in some instances increase (not decrease) risk (Neale et al 2017). For some individuals (i.e. street drug dealing or use of drugs by sex workers) payment maybe the only way individuals can viably participate without loss of income earning time; and reimbursement in cash rather than vouchers will be a necessity to enable participation (Sandberg 2008).

\section{Funding and research bids}

If a bid for a participatory project is to be made with clear evidence of involvement having informed it, then this involvement also needs funding. For traditional research bid preparation activity is part of the paid job role for academics. To ensure a parity and active involvement of others, it seems to be an important and logical consideration that some of the substance use commissioning, policy and organisational fora (referred to above) is also able to create funds and resource capacity for appropriate involvement to inform potential research project starting points (Minkler et al 2003).

Even assuming this informed prior application involvement, one of the biggest barriers to getting such research projects off the ground is often the successful acquisition of external funding. Research funds often sit in a competitive bid process, including blind peer review processes. These processes aspire to establish exactly what a research project is going to do, so how well detailed and predictable and/or reliable the methodology described is. These scoring methods often have a bias towards predictive/positivist experimental research over methods where determining the methodology is a part of the process and not fully determined prior to. Truly iterative and participatory approaches cannot provide such clarity before they have begun. In addition, and much like the ethics committee, the bids are assessed by panels of experts whose own experiences and understanding lie with controlled experiments, quantitative surveys and statistical modelling rather than qualitative involvement. Thus, there 
is a more inherent bias where participatory action approaches are neither understood, nor valued by those responsible for making such judgements. Typical of those sentiments is the following example that this author received from a recent 'friendly' reviewer post an award being made:

The use of participant researchers looks innovatory but pretty risky, and the sample size is very small. A small and potentially contentious methodology ... is unlikely to make a big difference to conclusions even if it worked.

This situation was recently acknowledged at the 2017 Alcohol Research UK Annual Conference, that in part has led to this special edition ${ }^{1}$.

\section{Data collection and analysis}

Whilst all forms of data collection tools can be used within participatory approaches there is often an inherent leaning towards the intrapersonal and relationship based inquires, so frequently qualitative methodology. Whilst this may regularly be done through focus groups and interviews with schedules and a range of semi-structured questions, participatory approaches also lend themselves to the use of arts and other creative data capture approaches (Bryant 2016). Iterative approaches (typical of highly qualitative methods to data collection and analysis, whereby the experience of one element feeds into and refines the next) feel highly resonant with involvement approaches that are seeking to develop collective understanding and inform change.

It is possible that PAIs will at these junctures require some formative input from the academics or others within the research team. Thus, some of the research team need at times to translate facilitator into educator roles. So, the stage here is the sharing of expertise and knowledge about research techniques. Active consideration must be given to how material often used in other classroom settings might need to be adapted for different audiences and learning needs.

It can be useful for PAIs to conduct the data collection method on each other. This provides: a) safe space to practice and receive feedback on, and refine techniques; and b) potential initial data that can be used within the wider data collection set. It might be that where data has been collected via film or audio, that the experienced researcher facilitator also watches and listens to the data, to provide supportive feedback to PAIs. Similarly, methods of analysis

\footnotetext{
${ }^{1}$ http://alcoholresearchuk.org/news/alcohol-research-uk-annual-conference-2017/
} 
might need to be explained or adapted to suit the needs of the PAI population. Consideration needs to be given to how best to support PAI involvement in analysis, so without assumption about access to and competence in IT. Some PAIs will want to be actively involved in the use of say SPSS or NVivo; but for others, a paper based or aural process maybe more suitable. Added reliability can occur with dual analysis approaches and then comparison of interpretations, so one approach for some PAIs and then a complimentary or additional one from the experienced or academic team members. An active but supportive role of experienced researchers within the cohort can act as an additional process of quality assurance.

Recruitment of respondents is likely to follow the same purposeful sampling methodology, using a combination of targeted advertisement (with active consideration given to mobile and social media methods) and snowballing through the existing substance use networks and relationships used in PAI recruitment. Research that utilises peer and recovery groups mean that individuals are known to each other within the community. Reflexive considerations of insider research approaches are required. Within this, identification of what proximity to potential respondents the PAIs are should be undertaken and used as inclusion or exclusion criteria; or passed onto another PAI within the project.

As PAIs spread out into the respective community and collect data, the experienced members of the team must be available for ongoing mentoring and support.

\section{Post data considerations}

Like other research methods, it is good to find a process by which emerging outcomes can be 'tested' out with those most likely to be impacted, and their responses to this can shape any final conclusions. This could include taking initial findings back to any initiating substance use fora or project advisory group. Active recovery communities are also likely to provide on-going spaces where PAIs can test and make sense of emerging findings and conclusions.

It is likely that commissioners of research will want to see traditional 'research reports'. Further, any academics involved will want to, and be under pressure to, publish within peer review journals. In both these regards it is important that a) the opportunity to participate in 'writing up' is extended to PAIs, and b) irrespective of their involvement in the writing up, they are fully acknowledged (with consent) as co-authors. However, some projects, some groups etc., may also identify other non-written ways of wanting to present research findings. The adoption of these seems important, especially when considering research as both 
involved and action orientated. The change implied in action is likely to come from the widest of dissemination approaches.

The implications suggest this paper, like other papers cited of the authors, might have involved some other substance use individuals as co-authors. However, we elected to be transparent in this being our thought piece and not a shared research project, but as in the introduction, to be clear we were not claiming originality of thought and indeed owed a debt to a vast number of previous collaborators.

Part of an action orientated methodology, which has process as important as outcomes, and considers outcomes for all, is about establishing sustainable PAI populations to then a) advise and support commissioning of future research, b) get involved in other projects, and c) act as peer mentors for future PAIs.

\section{Applied Framework}

It is possible to synthesise these considerations into a broad or proximate framework (model) comprising multiple stages.

Table 1: Model of stages of Participant Action Research approach

Insert table 1 here

Stages are iterative and overlap.

* These stages involve processes and organisations that are possibly external to the research team, so not fully within projects influence.

\section{Applied considerations}

This paper has been influenced by a diversity of previous and on-going research projects. However, given the considerations described, it has equally (if not more so) been informed by: many unsuccessful research bids, policy conversations, recovery group deliberations and reflections on the limitations of other research (including ours). This final section offers some of the learning we have acquired through these experiences.

PAR projects require a lot of (and at times freely given) energy and time, to ensure they are successful and sustainable. Several of the recent projects we have contributed to have come out of long-term prior existing relationships. In other words, we have been actively involved in those fora discussed in the earlier part of this paper. This requires the academic researcher 
to spend time out and about in the community. Notably, we have been active members of recovery group networks and partnerships, often giving skills and time just like any other volunteer. Successful bids and projects are far more likely to come from already established and trusting relationships. We have, as is consistent with other research approaches, spent time doing early, small and unfunded pilot formulations. There is a need to continue, especially in economic climates where organisations and universities increasingly seek to restrict activities to those associated with computerised workload management agendas, for researchers to articulate that such time spent is necessary and valuable - especially as this is required to be off site. There is scope here to use organisational good citizenship or social good agendas to help meet these goals.

That participatory research, especially that involving action (for change), is as much a political as it is research activity, has therefore been one of the earliest and consistent messages. Biskin et al (2013) identify how even the simple task of social work students being encouraged in the classroom to expect service user and carer involvement then meet resistance when wanting to account for whether they actually experience such in practice through a research project. So, whilst the service user involvement agenda is well established in substance use policy and provision agendas, it has yet to fully impact on the research world. Service user involvement has tended to primarily focus on the active participation of 'users' within treatment policy and provision agendas, rather than all users and ex users and including evaluation and research activities. In a recently completed review of the Welsh Governments 10-year alcohol (and drug) strategy there was no PAR material amongst the relevant data sets and evaluations (Author et al 2017).

PAR and PAI approaches require inclusivity (and measured risk taking) if they are to succeed in being different and provide alternative explanations. We have had expressed to us concerns about PAIs interviewing those who are still actively using and exposing their own vulnerability to relapse (which assumes that PAIs are abstinent - which need not necessarily be the case), and how rigid (or not) any criteria for PAIs needs to be. This in turn raises concerns for us about whether researchers could be tempted into using PAI recruitment methodologies which are too strict (or too controlling) unless they themselves are prepared to take a few risks. PAR research ought to have the capacity to involve the whole spectrum of use or not. It is by its nature risk taking rather than risk adverse. When working with those in recovery as PAIs it seems important to entrust to their already successfully developed notions of management and networks of support, rather than impose secondary researcher led 
frameworks. In fact, this makes us think that the success of PAI methodologies is also shaped by the characteristics of the research facilitator as it those of the PAIs recruited. Inclusivity and risk taking is thus required by those commissioning, evaluating, overseeing and undertaking research. This seems to be only a fair and reciprocal to the risk we ask of others in entrusting and sharing their experiences with us.

It feels as if over the last decade that the tide is finally turning. Indeed, the ARUK conference that is the precursor and inspiration for this special edition, is one obvious marker in this evolutionary journey. The explicit requirement to demonstrate involvement now appears to be a more regular element of research bid application and journal submission (i.e. British Medical Journal) process requirements. Indeed, we have had more bid success of late (albeit maybe it is just that we have got a bit better at that bit). Notably, and very recently, an acceptance of the validity of the contribution these methods can make to enhance a complexity of methods in understanding national policy, has been acknowledged by Health Scotland in its commissioning of participatory methods as one of the streams within the evaluation of the impact of minimum unit pricing on harmful drinkers (NHS Health Scotland 2017).

\section{Concluding discussion}

At one level there is nothing revolutionary in the principles of PAR or the methodological considerations explored within this paper. In part, they just feel like good conscious and reflexive research practices. However, at another level they seek to comprehensively resonate with aspirations for greater service user involvement in policy, practice and research activities. They have a feel of the ideological, a set of best laid aspirations and intentions. In this sense the revolutionary comes from trying to meet as many of the ambitions as possible within each project, while contributing to an overall picture of change and challenge to an existing order that places expert led controlling experimental research at the pinnacle of perceived research hierarchies.

It is possible to reduce these complex discussions into three clear reasons why we should do and see more PAR/PAI research within alcohol and other drug studies. Firstly, this feels like a moral imperative. It is just the right thing to do. There has been an explosion in service user involvement in policy and service provision for substance use, and this needs to be matched by those researching such. Substances are widely consumed in society, including by researchers. The boundaries between an 'us and them' population often maintained by 
researchers in this instance seems particularly false. It maybe that we need to turn the traditional research ethics preoccupation with protecting the vulnerable on its head and into one of entrust, empower and respect. Secondly, this is a political issue. It raises fundamental questions of ontology and epistemology. A challenge to a dominant and vested interest about who does research and how. It asks questions of who is the 'expert'. It asks that research has an impact beyond the vested interest of the academic career and the research frameworks that academic institutions are increasingly judged by. Finally, and this is the purpose of research, new methodologies help create new understanding. There is more than one way to know how. It is a direct and appropriate response to Orford's (2008) seminal paper that argued for substance use research to move beyond its preoccupation with the randomised control trial. These are methodologies that enable us to gain a greater insight into the nature of experiences and relationships that are at the core of understanding why individuals develop difficulties regarding their substance use and how they might best be supported in developing healthier lifestyles.

It is possible to see two overlapping 'new' waves at work here. Where research has accepted the role of the sociological and qualitative to compliment the experimental and quantitative, it has yet to fully embrace moves to take this outside of the academy. Similarly, where substance use has embraced harm reduction and whole population agendas as a response to narrow disease model understandings, it has yet to fully reconcile itself with some of the newer debates and understanding about recovery and the increased control and involvement of those most affected. This paper simply seeks to contribute to these journeys.

\section{References}

Author (2016)

Author (2017)

Author et al. (2011)

Author et al (2017).

Arnstein, S. R. (1969) "A Ladder of Citizen Participation," JAIP, 35(4). 216-224

Biskin, S. Barcroft, V. Livingston, W. and Snape, S (2013). Exploring service user and care involvement on a social work degree programme, Social Work Education: The International Journal, 32(3), 301-316. 
Bradbury, H., and Reason, P. (2003). Action research: An opportunity for revitalizing research purpose and practices. Qualitative Social Work, 2(2), 155-175

Brett, J., Staniszewska, S., Mockford, C., Herron-Marx, S., Hughes, J., Tysall, C. and Suleman, R. (2014), Mapping the impact of patient and public involvement on health and social care research: a systematic review. Health Expectations, 17(5), 637-650

Bryant, L. (2016) Introduction in Bryant, L. ed (2016) Critical and Creative Research Methodologies in Social Work, Routledge London (75-92).

Bryman, A. (2008) Social Research Methods Oxford, Oxford University Press.

Carey, M. (2010) Should I stay or should I go? Practical, ethical and political challenges to 'Service User' Participation within Social work research. Qualitative Social Work 10(2), 224-243.

Ennis and Wykes (2013) Impact of patient involvement in mental health research: longitudinal study The British Journal of Psychiatry 203: 381-386.

Fine, G. A and Hancock, B. H.(2017) The new ethnographer at work Qualitative Research $17(2), 260-268$.

Fry, C.: Hall, W; Ritter, A and Jenkinson, R (2006) The ethics of paying drug users the ethics of paying drug users who participate in research: a review and practical recommendations who participate in research: a review and practical recommendations. Journal of Empirical Research on Human Research Ethics,. 21-36.

Gilbert, N (2008) Researching Social Life London, Sage.

Humphries, B (2008) Social Work Research for Social Justice Basingstoke Palgrave Macmillan

McLaughlin, H. (2010) 'Keeping service user involvement in research honest', British Journal of Social Work, 40(5),. 1591-1608.

Minkler, M., Blackwell, A. G., Thompson, M., \& Tamir, H. (2003). Community-Based

Participatory Research: Implications for Public Health Funding. American Journal of Public Health, 93(8), 1210-1213.

NHS Health Scotland (2017) Evaluation of minimum unit pricing http://www.healthscotland.scot/health-topics/alcohol/evaluation-of-minimum-unit-pricing 
[Accessed 01-08-2017]

Neale, J; Black, L; Getty, M; Hogan, C; Lennon, P; Lora, C; McDonald, R; Strang, J;

Tompkins, C; Usher, J, Villa, G; and A, Wylie (2017): Paying participants in addiction research: is cash king?, Journal of Substance Use Advanced Online Access

http://dx.doi.org/10.1080/14659891.2016.1259367 [Accessed 01-08-2017].

Orford, J (2008) Asking the right questions in the right way: the need for a shift in research on psychological treatments for addiction Addiction, 103(6), 875-85.

Reason, P and Bradbury H (Eds.) (2001) The Handbook of Action Research. London, UK; Thousand Oaks, CA: Sage

Ritter, A., Fry, C. L., \& Swan, A. (2003). The ethics of reimbursing drug users for public health research interviews: What price are we prepared to pay? International Journal of Drug Policy, 14(1), 1-3.

Sandberg, S. (2008) 'Black drug dealers in a white welfare state: Cannabis dealing and street capital in Norway', British Journal of Criminology, 48(5), 604-619.

Tedmanson, D (2016) Ngapartji Ngapartji - Narratives of Reciprocity in 'Yarning Up' Participatory Research in Bryant, L. ed (2016) Critical and Creative Research Methodologies in Social Work, Routledge London (75-92).

Tolich, M. (2004) Internal Confidentiality: When Confidentiality Assurances Fail Relational Informants Qualitative Sociology 27(1), 101-106.

Voorberg, W. H.; Bekkers, V. J. J. M and Tummers, L.G.(2015) A Systematic Review of Co-Creation and Co-Production: Embarking on the social innovation journey, Public Management Review, 17(9), 1333-1357.

Whyte, W.F (1993) Street Corner Society: The Social Structure of an Italian Slum (4 ${ }^{\text {th }}$ edn) Chicago, University of Chicago Press. 


\title{
$\underline{\text { Participatory Action Research (PAR) Research - Critical methodological considerations }}$
}

Authors

Dr. Wulf Livingston - Glyndwr University

Andrew Perkins - Figure 8 Consultancy Services Ltd.

Correspondence address - Wulf Livingston, Glyndwr University, School of Life and Social Sciences, PP13, Plas Coch Campus, Mold Road, Wrexham, Wales, LL11 2AW.

W.livingston@glyndwr.ac.uk

\begin{abstract}
Purpose: The purpose of this paper is to explore a range of key deliberations with regards to adopting Participatory Action Research (PAR) and Privileged Access Interviewer (PAI) approaches and methodologies within research on substance use

Design/methodology/approach: This paper is a reflective piece, it adopts a mixture of applied practice and theory considerations. These conceptualisations capture what are still relatively early understandings and uses of such methodologies, acquired across several decades of research and service provision experiences. The paper is structured around some of the sequences of the research process and as such provides a broad framework for such approaches.
\end{abstract}

Findings: PAR and PAI approaches utilise several key theoretical considerations. There are many critical issues associated with adopting these approaches, including those of ethics, funding, involvement, language, resources and support. Three key principle reasons (moral, political and research based), help explain why we should see more adoption of such approaches in substance use related research.

Research limitations/implications: This paper represents author views which are by their nature very subjective.

Practical implications: Implementation of the key considerations highlighted within this paper can lead to an active adoption of PAR and PAI methodologies within alcohol and drug research. Increasing the use of such methodologies will allow commissioners, researchers and 
service providers to develop a more nuanced understanding of the experiences of and responses to alcohol and drug use.

Originality/value: This paper captures critical conversations at a time of increased calls for service user involvement across all aspects of alcohol and other drug provision, including evaluation and research.

Key Words: Alcohol and Drugs, Involvement, Participatory Action Research, Research Methodologies, Substance Use

\section{Introduction}

This paper is explicitly the current views of its named authors. However, like all research papers, it builds upon previous experiences and projects (for example Biskin et al 2013, Livingston et al 2011) and previous writing (Livingston 2016, 2017). Therefore, much of what is offered emanates from co-production activities with other actors which have influenced its formulation. Given its nature, it would be inappropriate to not start by stating that this paper is the consequence of all the generous sharing by and with all those we have worked with across numerous years in research and service provision. We are grateful to them for educating us and as such we feel advocates rather than originators of the sentiments contained within this paper.

Participant Action Research (PAR) combines two separate research concepts:

- Participation - active involvement of 'subjects' in the research process; and

- Action - defining social problems and solving them.

It sits within a spectrum of what is considered patient, public or service user involvement. The movement to increased participation is often concentrated on provision and receipt of health and social care services, but also includes research into the effectiveness of services too (Brett et al 2014, Voorberg 2015). An early defining model of this spectrum was Arnstein's (1969) ladder of citizen participation which suggested a full spectrum from manipulation to citizen control. In research terms we might suggest some of the positions along the spectrum as:

- Non-Participation (manipulation) - service users partake purely as respondents from whom data is collected. 
- Degrees of moderate involvement - consultation or involvement in steering groups only.

- Significant involvement - delegated and designated roles within the research as researchers.

- Participatory Research - involved in the need for and commissioning of research, and/or as full team members from research bid through to final report.

The two concepts of PAR bring different elements and understanding to the research process, including that of alcohol and drugs.

Firstly:

Participatory - this is what Gilbert (2008) refers to as doing with and for, rather than on others. It is thus concerned with definitions of expertise and knowledge and who controls these. It comes with what Humphries (2008) identifies as having several principles:

- a bottom up approach with a focus on locally defined priorities, processes and perspectives;

- striving for equalising power among researchers and researched;

- a process characterised by a genuine dialogue between researcher and researched;

- control over definition of problems, methods, analysis and actions is with those most affected by the study;

- the emphasis is on processes as much as on outcomes; and

- the role of the researcher is one of facilitator and catalyst rather than director.

Secondly:

Action - proposes that action researcher and members of a social setting collaborate in the understanding of a problem and in the development of a solution based on this understanding (Bryman 2008). This is supported by an emphasis on:

- nonintrusive collaboration (including ownership of the project by the group);

- mutual trust and genuine respect;

- solidarity (all humanity is connected by a common journey and shared destiny);

- mutuality and equality (everyone's interests are important);

- a focus on process (informal interaction that goes beyond a detached working relationship and respects others' cultures); and 
- language as an expression of culture and power.

Action research seeks intended consequences and expects elements of change to be experienced by all. It pursues to overtly improve the social situation with explicit practical application and political activity. It can occur across several activities, for example: organisational change, community development, new projects, practitioner research and social injustice.

The overall approach can be summarised as concerning itself with 'People, Power and Praxis' (Gilbert 2008) where traditional academic researchers translate their role into one of facilitating the goals of their co-researchers. Carey (2010) echoes these sentiments in which three key considerations are raised: practical impediments, ethical implications and political dilemmas. He goes onto caution that there are possibilities that participation in research can mirror some of the current preoccupations in wider policy and provision, where participation may be encouraged or increased but not necessarily be successful in addressing the power dynamics; and may even exasperate them.

Privileged Access Interviewers (PAI) is a term that best captures why such methods are especially well suited for research inquiries into areas of activity and with people in experiences that are subject to societal marginalisation and often referred to as 'hard to reach'. These include those of substance use. The approach is political apposite where there is a need to reach into certain populations who are perhaps not readily captured by traditional research methodology. There are distinct overlaps with the ethnographic approaches drawn from social anthropology (Fine and Hancock 2017), and the essential role of those with access as established through Whyte's (1993) seminal text and his relationship with Doc. Ennis and Wykes (2013) concluded that such involvement of service users in the research process enabled greater levels of recruitment to projects. Further, participatory approaches (i.e. those emphasising what can be considered as co-production) have a resonance and value in understanding the experiences of marginalised populations (Tedmanson 2016), including alcohol and drug use.

The principles of these approaches like most research techniques be applied to a range of design, data collection and analysis methods. This said, there is to some degree an inherent bias towards the subjective rather than the objective. Thus, many articulate for the use of an extensive range of qualitative written, visual and textual data collection methods (Bryant 
2016) to compliment the traditional dominant paradigm for random control trials, statistics and surveys.

Within these discourses the use of terminology implies ontological and methodological positions. The ethical, morale and methodological implications of this language are explored further on; but for consistency this paper, from hereon in, refers to those whom are actively involved in the research as participants and those who contribute or offer data examples as respondents. For expediency it adopts substance use to capture the diversity of both 'substances' (alcohol, illicit, legal and illegal drugs) and 'use' (dependency, excessive, harmful, hazardous and recreational).

\section{Starting Points}

These approaches have several assumptions (or givens) that might be considered as preexisting contextual considerations.

Whilst the idea that a group of alcohol and drug service users will just wander up to a university and ask for assistance in a research project might sound like the optimum and theoretical starting point (and indeed does occasionally happen), it is likely (and should be likely if co-production is indeed an increasingly wider commissioning, policy and service provision norm) that ideas are generated from within existing involvement activity. This could or should happen in substance use organisations or fora where meaningful participation is already well established with regards to other business or activities. This methodology therefore demands that initial conversations have been reciprocal and not unduly led by agencies/researchers to meet their own agendas. Thus, involvement prior to design or research bid application moves research further along the possible spectrum of participation.

From here it is appropriate to have one or two dedicated conversations/meetings that scope out a project. These might well want to involve others not deemed as participants as well as early project initiators. This is important to ensure that the research is supported, welcomed and has a good level of stakeholder engagement and involvement from the start. These early conversations need to include explicit exploration of ethical and resourcing issues. Such solid foundations of shared understanding are important to help ease future resistance when goals are directed towards political change.

It is likely, if not desirable or expected, that such a stage maybe the precursor to a formal funding application. Although, as outlined below, acquiring funding is not without its 
difficulties. Ideally in such instances applications are made with participants rather than on their behalf.

It feels important to emphasise that, in these early meetings, service user and participant voice is strong and not of a singular or representative type. Indeed, some might argue they need to be the majority for it to be truly participative, and the involvement of other professionals and researchers is for consultation (McLaughlin 2010).

\section{Identifying and recruiting participants}

In many instances those individuals involved in the initial and scoping conversations may well be those identified as the participants or PAIs. It feels important that potential participation is invited across many roles and responding to a variety of interest and skills, such as: project advisories or consultants, full blown participants, advertisers, recruiters, respondents and supporters. While initial conversations may generate enough involvement, in many instances there is likely to be the need for further recruitment - especially for PAI type projects. This will need to follow a purposeful sampling methodology, using a combination of targeted advertisement (with active consideration given to mobile and social media methods) and snowballing through existing substance use networks, relationships and recovery organisations.

There comes a point in participatory methods, if this has not happened fully at inception, where any project needs to ensure its direction is highly participant led. At this juncture the research team (PAI and supporting academics) need to possibly withdraw from wider stakeholder discussions and begin to enable an approach which is very much service led, rather than informed. The role of the (academic) researcher here is to facilitate discussions and understanding among the participants, and support them to agree upon the specific methods of inquiry.

Substance use research has the possibility to see co-production beyond the service user group and partnership could see carers, families, practitioners or students become the participant population.

\section{Language and Terminology}

Early formulations of this paper were borne out of and reflect struggles with language. Much research literature frequently refers to participants. When in the context of an understanding of genuine partnership involvement, what is being referred to is those from whom data has 
been collected. The use of participant almost seems a hangover of a subject involved in a controlled experiment, rather than any sense of any co-production; the exceptions perhaps being those engaged in ethnography or discourse analysis. For us, the ambiguity and confusion were cleared by choosing to be firm in distinguishing between those from whom we collect data (respondents), and those who actively participate in the other aspects of the research process (participants).

While such deliberations may appear of semantics, they are in fact rooted in issues of power. They challenge perceptions of 'us and them' populations. At the heart of them lies a transparent declaration of whether researchers are distinct from (expert and controlling), or sharing in the same human experience (indeed most alcohol researchers are drinkers). The latter position begins to ask fundamental questions of whether one truth or measurable actuality exists, rather than being a construct of any given (research) process. Furthermore, it raises questions of who is the expert and in what capacity. It also suggests the equal validity of all research methods, rather than supporting a hierarchy of the traditional or dominant. Finally, it implies the assumption of a sharing of access to resources and rewards from the research process.

\section{Ethics}

As research, normal ethical considerations and processes must be accounted for. Projects will need to undertake appropriate due research ethics processes. It is possible that where ethics boards are predominantly used to, or dominated by traditional positivist and experimental type research approaches, that understanding of (and support for) PAR approaches maybe more limited. However, it is our experience that ethical approval is gained when attention is paid to specific key considerations; notably issues of boundaries and researcher confidence.

These approaches have a resonance with ethnography, which in turn helps to inform the management (or not) of boundary issues. Researchers are considered, if not expected, to be an active part of the community. Indeed, it is the opposite of aloof non-participatory observation which, in terms of the politics of involvement, might be considered a more exploitative and unethical approach. Active researcher participation offers the opportunity of more realistic, transparent and trustworthy interactions. It works with continuums of populations and communities, rather than suggestions of 'us and them' populations. Working within discreet populations (as accessed via a PAI) challenges the boundaries of what is considered normal confidentiality for other research methodologies. Tolich (2004) 
acknowledges that an overt understanding of this helps accept the limits in the principles of confidentiality. Insiders are more likely to recognise what other insiders have said. He concludes that internal confidentiality is distinct from external confidentiality and suggests the assurances for protection against identification is with those who were not subjects of the research, rather than within the discreet population cohort or community.

Because the methodology described here is a) not as deterministic or predictable in its course of action and b) process orientated, then the ethical requirement is for confidence in the researcher and/or research team (as much as the prescription of methods) and the successful management of what can appear as more fluid boundaries between the researcher and the researched. Ethics committee confidence is often, as with other methods, about any relevant prior experience of the researcher. One of the authors (as a registered social worker) has found it is important to stress equally the oversight of practice and research ethics. Thus, the process of being held accountable to a professional regulatory body compliment those of research ethics, as might a social work qualification compliment a $\mathrm{PhD}$. This is because many of the research ethics issues are foremost practice dilemmas.

As might be expected, there is also regular concern raised about the use of payments for participants in this area of research. The ethical concerns often fall into two considerations: those of undue incentive to participate (Ritter et al 2003), and/or payment leading to risk of harm, notably with the possibilities of monies being spent on substances. However, many researchers have now clearly articulated why genuine participation (issues of power) require this group of users to be treated the same as others and that payment is a requisite (Fry et al 2006, Neale et al 2017, Sandberg 2008). Fry et al (2006) in their article conclude “...research payments are ethically acceptable in most circumstances of addictions research, but should be closely scrutinized in situations where these may exacerbate existing harms or create additional risks for participants and investigators" (p21). This counter argument therefore stems around payments as justifiable and fair reimbursement for time given and expenses occurred. The concerns about cash being spent on substances is usually compromised by providing individuals with high street shopping vouchers that cannot be exchanged for alcohol or cigarettes. Participants in research studies have expressed that the use of vouchers can present implied lack of trust or feel paternalistic and may even in some instances increase (not decrease) risk (Neale et al 2017). For some individuals (i.e. street drug dealing or use of drugs by sex workers) payment maybe the only way individuals can viably participate 
without loss of income earning time; and reimbursement in cash rather than vouchers will be a necessity to enable participation (Sandberg 2008).

\section{Funding and research bids}

If a bid for a participatory project is to be made with clear evidence of involvement having informed it, then this involvement also needs funding. For traditional research bid preparation activity is part of the paid job role for academics. To ensure a parity and active involvement of others, it seems to be an important and logical consideration that some of the substance use commissioning, policy and organisational fora (referred to above) is also able to create funds and resource capacity for appropriate involvement to inform potential research project starting points (Minkler et al 2003).

Even assuming this informed prior application involvement, one of the biggest barriers to getting such research projects off the ground is often the successful acquisition of external funding. Research funds often sit in a competitive bid process, including blind peer review processes. These processes aspire to establish exactly what a research project is going to do, so how well detailed and predictable and/or reliable the methodology described is. These scoring methods often have a bias towards predictive/positivist experimental research over methods where determining the methodology is a part of the process and not fully determined prior to. Truly iterative and participatory approaches cannot provide such clarity before they have begun. In addition, and much like the ethics committee, the bids are assessed by panels of experts whose own experiences and understanding lie with controlled experiments, quantitative surveys and statistical modelling rather than qualitative involvement. Thus, there is a more inherent bias where participatory action approaches are neither understood, nor valued by those responsible for making such judgements. Typical of those sentiments is the following example that this author received from a recent 'friendly' reviewer post an award being made:

The use of participant researchers looks innovatory but pretty risky, and the sample size is very small. A small and potentially contentious methodology ... is unlikely to make a big difference to conclusions even if it worked.

This situation was recently acknowledged at the 2017 Alcohol Research UK Annual Conference, that in part has led to this special edition ${ }^{1}$.

\footnotetext{
${ }^{1}$ http://alcoholresearchuk.org/news/alcohol-research-uk-annual-conference-2017/
} 


\section{Data collection and analysis}

Whilst all forms of data collection tools can be used within participatory approaches there is often an inherent leaning towards the intrapersonal and relationship based inquires, so frequently qualitative methodology. Whilst this may regularly be done through focus groups and interviews with schedules and a range of semi-structured questions, participatory approaches also lend themselves to the use of arts and other creative data capture approaches (Bryant 2016). Iterative approaches (typical of highly qualitative methods to data collection and analysis, whereby the experience of one element feeds into and refines the next) feel highly resonant with involvement approaches that are seeking to develop collective understanding and inform change.

It is possible that PAIs will at these junctures require some formative input from the academics or others within the research team. Thus, some of the research team need at times to translate facilitator into educator roles. So, the stage here is the sharing of expertise and knowledge about research techniques. Active consideration must be given to how material often used in other classroom settings might need to be adapted for different audiences and learning needs.

It can be useful for PAIs to conduct the data collection method on each other. This provides: a) safe space to practice and receive feedback on, and refine techniques; and b) potential initial data that can be used within the wider data collection set. It might be that where data has been collected via film or audio, that the experienced researcher facilitator also watches and listens to the data, to provide supportive feedback to PAIs. Similarly, methods of analysis might need to be explained or adapted to suit the needs of the PAI population. Consideration needs to be given to how best to support PAI involvement in analysis, so without assumption about access to and competence in IT. Some PAIs will want to be actively involved in the use of say SPSS or NVivo; but for others, a paper based or aural process maybe more suitable. Added reliability can occur with dual analysis approaches and then comparison of interpretations, so one approach for some PAIs and then a complimentary or additional one from the experienced or academic team members. An active but supportive role of experienced researchers within the cohort can act as an additional process of quality assurance.

Recruitment of respondents is likely to follow the same purposeful sampling methodology, using a combination of targeted advertisement (with active consideration given to mobile and 
social media methods) and snowballing through the existing substance use networks and relationships used in PAI recruitment. Research that utilises peer and recovery groups mean that individuals are known to each other within the community. Reflexive considerations of insider research approaches are required. Within this, identification of what proximity to potential respondents the PAIs are should be undertaken and used as inclusion or exclusion criteria; or passed onto another PAI within the project.

As PAIs spread out into the respective community and collect data, the experienced members of the team must be available for ongoing mentoring and support.

\section{Post data considerations}

Like other research methods, it is good to find a process by which emerging outcomes can be 'tested' out with those most likely to be impacted, and their responses to this can shape any final conclusions. This could include taking initial findings back to any initiating substance use fora or project advisory group. Active recovery communities are also likely to provide on-going spaces where PAIs can test and make sense of emerging findings and conclusions.

It is likely that commissioners of research will want to see traditional 'research reports'. Further, any academics involved will want to, and be under pressure to, publish within peer review journals. In both these regards it is important that a) the opportunity to participate in 'writing up' is extended to PAIs, and b) irrespective of their involvement in the writing up, they are fully acknowledged (with consent) as co-authors. However, some projects, some groups etc., may also identify other non-written ways of wanting to present research findings. The adoption of these seems important, especially when considering research as both involved and action orientated. The change implied in action is likely to come from the widest of dissemination approaches.

The implications suggest this paper, like other papers cited of the authors, might have involved some other substance use individuals as co-authors. However, we elected to be transparent in this being our thought piece and not a shared research project, but as in the introduction, to be clear we were not claiming originality of thought and indeed owed a debt to a vast number of previous collaborators.

Part of an action orientated methodology, which has process as important as outcomes, and considers outcomes for all, is about establishing sustainable PAI populations to then a) advise 
and support commissioning of future research, b) get involved in other projects, and c) act as peer mentors for future PAIs.

\section{Applied Framework}

It is possible to synthesise these considerations into a broad or proximate framework (model) comprising multiple stages.

Table 1: Model of stages of Participant Action Research approach

Insert table 1 here

Stages are iterative and overlap.

* These stages involve processes and organisations that are possibly external to the research team, so not fully within projects influence.

\section{Applied considerations}

This paper has been influenced by a diversity of previous and on-going research projects. However, given the considerations described, it has equally (if not more so) been informed by: many unsuccessful research bids, policy conversations, recovery group deliberations and reflections on the limitations of other research (including ours). This final section offers some of the learning we have acquired through these experiences.

PAR projects require a lot of (and at times freely given) energy and time, to ensure they are successful and sustainable. Several of the recent projects we have contributed to have come out of long-term prior existing relationships. In other words, we have been actively involved in those fora discussed in the earlier part of this paper. This requires the academic researcher to spend time out and about in the community. Notably, we have been active members of recovery group networks and partnerships, often giving skills and time just like any other volunteer. Successful bids and projects are far more likely to come from already established and trusting relationships. We have, as is consistent with other research approaches, spent time doing early, small and unfunded pilot formulations. There is a need to continue, especially in economic climates where organisations and universities increasingly seek to restrict activities to those associated with computerised workload management agendas, for researchers to articulate that such time spent is necessary and valuable - especially as this is required to be off site. There is scope here to use organisational good citizenship or social good agendas to help meet these goals. 
That participatory research, especially that involving action (for change), is as much a political as it is research activity, has therefore been one of the earliest and consistent messages. Biskin et al (2013) identify how even the simple task of social work students being encouraged in the classroom to expect service user and carer involvement then meet resistance when wanting to account for whether they actually experience such in practice through a research project. So, whilst the service user involvement agenda is well established in substance use policy and provision agendas, it has yet to fully impact on the research world. Service user involvement has tended to primarily focus on the active participation of 'users' within treatment policy and provision agendas, rather than all users and ex users and including evaluation and research activities. In a recently completed review of the Welsh Governments 10-year alcohol (and drug) strategy there was no PAR material amongst the relevant data sets and evaluations (Livingston et al 2017).

PAR and PAI approaches require inclusivity (and measured risk taking) if they are to succeed in being different and provide alternative explanations. We have had expressed to us concerns about PAIs interviewing those who are still actively using and exposing their own vulnerability to relapse (which assumes that PAIs are abstinent - which need not necessarily be the case), and how rigid (or not) any criteria for PAIs needs to be. This in turn raises concerns for us about whether researchers could be tempted into using PAI recruitment methodologies which are too strict (or too controlling) unless they themselves are prepared to take a few risks. PAR research ought to have the capacity to involve the whole spectrum of use or not. It is by its nature risk taking rather than risk adverse. When working with those in recovery as PAIs it seems important to entrust to their already successfully developed notions of management and networks of support, rather than impose secondary researcher led frameworks. In fact, this makes us think that the success of PAI methodologies is also shaped by the characteristics of the research facilitator as it those of the PAIs recruited. Inclusivity and risk taking is thus required by those commissioning, evaluating, overseeing and undertaking research. This seems to be only a fair and reciprocal to the risk we ask of others in entrusting and sharing their experiences with us.

It feels as if over the last decade that the tide is finally turning. Indeed, the ARUK conference that is the precursor and inspiration for this special edition, is one obvious marker in this evolutionary journey. The explicit requirement to demonstrate involvement now appears to be a more regular element of research bid application and journal submission (i.e. British Medical Journal) process requirements. Indeed, we have had more bid success of late (albeit 
maybe it is just that we have got a bit better at that bit). Notably, and very recently, an acceptance of the validity of the contribution these methods can make to enhance a complexity of methods in understanding national policy, has been acknowledged by Health Scotland in its commissioning of participatory methods as one of the streams within the evaluation of the impact of minimum unit pricing on harmful drinkers (NHS Health Scotland 2017).

\section{Concluding discussion}

At one level there is nothing revolutionary in the principles of PAR or the methodological considerations explored within this paper. In part, they just feel like good conscious and reflexive research practices. However, at another level they seek to comprehensively resonate with aspirations for greater service user involvement in policy, practice and research activities. They have a feel of the ideological, a set of best laid aspirations and intentions. In this sense the revolutionary comes from trying to meet as many of the ambitions as possible within each project, while contributing to an overall picture of change and challenge to an existing order that places expert led controlling experimental research at the pinnacle of perceived research hierarchies.

It is possible to reduce these complex discussions into three clear reasons why we should do and see more PAR/PAI research within alcohol and other drug studies. Firstly, this feels like a moral imperative. It is just the right thing to do. There has been an explosion in service user involvement in policy and service provision for substance use, and this needs to be matched by those researching such. Substances are widely consumed in society, including by researchers. The boundaries between an 'us and them' population often maintained by researchers in this instance seems particularly false. It maybe that we need to turn the traditional research ethics preoccupation with protecting the vulnerable on its head and into one of entrust, empower and respect. Secondly, this is a political issue. It raises fundamental questions of ontology and epistemology. A challenge to a dominant and vested interest about who does research and how. It asks questions of who is the 'expert'. It asks that research has an impact beyond the vested interest of the academic career and the research frameworks that academic institutions are increasingly judged by. Finally, and this is the purpose of research, new methodologies help create new understanding. There is more than one way to know how. It is a direct and appropriate response to Orford's (2008) seminal paper that argued for substance use research to move beyond its preoccupation with the randomised control trial. 
These are methodologies that enable us to gain a greater insight into the nature of experiences and relationships that are at the core of understanding why individuals develop difficulties regarding their substance use and how they might best be supported in developing healthier lifestyles.

It is possible to see two overlapping 'new' waves at work here. Where research has accepted the role of the sociological and qualitative to compliment the experimental and quantitative, it has yet to fully embrace moves to take this outside of the academy. Similarly, where substance use has embraced harm reduction and whole population agendas as a response to narrow disease model understandings, it has yet to fully reconcile itself with some of the newer debates and understanding about recovery and the increased control and involvement of those most affected. This paper simply seeks to contribute to these journeys.

\section{References}

Arnstein, S. R. (1969) "A Ladder of Citizen Participation," JAIP, 35(4). 216-224

Biskin, S. Barcroft, V. Livingston, W. and Snape, S (2013). Exploring service user and care involvement on a social work degree programme, Social Work Education: The International Journal, 32(3), 301-316.

Bradbury, H., and Reason, P. (2003). Action research: An opportunity for revitalizing research purpose and practices. Qualitative Social Work, 2(2), 155-175

Brett, J., Staniszewska, S., Mockford, C., Herron-Marx, S., Hughes, J., Tysall, C. and Suleman, R. (2014), Mapping the impact of patient and public involvement on health and social care research: a systematic review. Health Expectations, 17(5), 637-650

Bryant, L. (2016) Introduction in Bryant, L. ed (2016) Critical and Creative Research Methodologies in Social Work, Routledge London (75-92).

Bryman, A. (2008) Social Research Methods Oxford, Oxford University Press.

Carey, M. (2010) Should I stay or should I go? Practical, ethical and political challenges to 'Service User' Participation within Social work research. Qualitative Social Work 10(2), $224-243$.

Ennis and Wykes (2013) Impact of patient involvement in mental health research: longitudinal study The British Journal of Psychiatry 203: 381-386. 
Fine, G. A and Hancock, B. H.(2017) The new ethnographer at work Qualitative Research $17(2), 260-268$.

Fry, C.: Hall, W; Ritter, A and Jenkinson, R (2006) The ethics of paying drug users the ethics of paying drug users who participate in research: a review and practical recommendations who participate in research: a review and practical recommendations. Journal of Empirical Research on Human Research Ethics,. 21-36.

Gilbert, N (2008) Researching Social Life London, Sage.

Humphries, B (2008) Social Work Research for Social Justice Basingstoke Palgrave Macmillan

Livingston W. (2016) Responding to Orford: Diverse methodological aspirations Alcohol Research UK Early Researcher Symposium, March 15th Birmingham http://www.fead.org.uk/video/dr-wulf-livingston-responding-to-orford-diversemethodological-aspirations/ [Accessed 01-08-2017]

Livingston, W (2017) Participatory Action Research (PAR) Research: Considerations for a qualitative methodological approach. Kettil Bruun Society: Symposium (Sheffield) June 5-9th (Paper available).

Livingston, W. Baker, M. Atkins, B and Jobber, S. (2011) 'A tale of the spontaneous emergence of a recovery group and the characteristics that are making it thrive: Exploring the politics and knowledge of recovery' The Journal of Groups in Addiction and Recovery 6(1), 176-196.

Livingston, W; Perkins, A; McCarthy, T; Madoc-Jones, I; Wighton, S; Wilson, F and Nicholas, D (2017). Review of Working Together to Reduce Harm: Final Report (Due for publication January 2018).

McLaughlin, H. (2010) 'Keeping service user involvement in research honest', British Journal of Social Work, 40(5),. 1591-1608.

Minkler, M., Blackwell, A. G., Thompson, M., \& Tamir, H. (2003). Community-Based Participatory Research: Implications for Public Health Funding. American Journal of Public Health, 93(8), 1210-1213.

NHS Health Scotland (2017) Evaluation of minimum unit pricing http://www.healthscotland.scot/health-topics/alcohol/evaluation-of-minimum-unit-pricing 
[Accessed 01-08-2017]

Neale, J; Black, L; Getty, M; Hogan, C; Lennon, P; Lora, C; McDonald, R; Strang, J;

Tompkins, C; Usher, J, Villa, G; and A, Wylie (2017): Paying participants in addiction research: is cash king?, Journal of Substance Use Advanced Online Access

http://dx.doi.org/10.1080/14659891.2016.1259367 [Accessed 01-08-2017].

Orford, J (2008) Asking the right questions in the right way: the need for a shift in research on psychological treatments for addiction Addiction, 103(6), 875-85.

Reason, P and Bradbury H (Eds.) (2001) The Handbook of Action Research. London, UK; Thousand Oaks, CA: Sage

Ritter, A., Fry, C. L., \& Swan, A. (2003). The ethics of reimbursing drug users for public health research interviews: What price are we prepared to pay? International Journal of Drug Policy, 14(1), 1-3.

Sandberg, S. (2008) 'Black drug dealers in a white welfare state: Cannabis dealing and street capital in Norway', British Journal of Criminology, 48(5), 604-619.

Tedmanson, D (2016) Ngapartji Ngapartji - Narratives of Reciprocity in 'Yarning Up' Participatory Research in Bryant, L. ed (2016) Critical and Creative Research Methodologies in Social Work, Routledge London (75-92).

Tolich, M. (2004) Internal Confidentiality: When Confidentiality Assurances Fail Relational Informants Qualitative Sociology 27(1), 101-106.

Voorberg, W. H.; Bekkers, V. J. J. M and Tummers, L.G.(2015) A Systematic Review of Co-Creation and Co-Production: Embarking on the social innovation journey, Public Management Review, 17(9), 1333-1357.

Whyte, W.F (1993) Street Corner Society: The Social Structure of an Italian Slum (4 ${ }^{\text {th }}$ edn) Chicago, University of Chicago Press. 